\title{
Why does Amazon precipitation decrease when tropical forests respond to increasing $\mathrm{CO}_{2}$ ?
}

\author{
B. Langenbrunner ${ }^{1}$, M. S. Pritchard ${ }^{1}$, G. J. Kooperman ${ }^{2}$, and J. T. Randerson ${ }^{1}$ \\ ${ }^{1}$ Department of Earth System Science, University of California, Irvine, California, USA \\ ${ }^{2}$ Department of Geography, University of Georgia, Athens, Georgia, USA
}

\section{Key Points:}

- Increasing $\mathrm{CO}_{2}$ over the Amazon causes a drier, warmer, and expanded boundary layer and reduces basin-wide rainfall within the first day

- On synoptic timescales, enhanced lower free troposphere moisture is advected westward by the low-level jet, increasing Andean rainfall

- A wetter Andes, dryer Amazon pattern is consistent across regional and global climate models and parameterized versus resolved convection
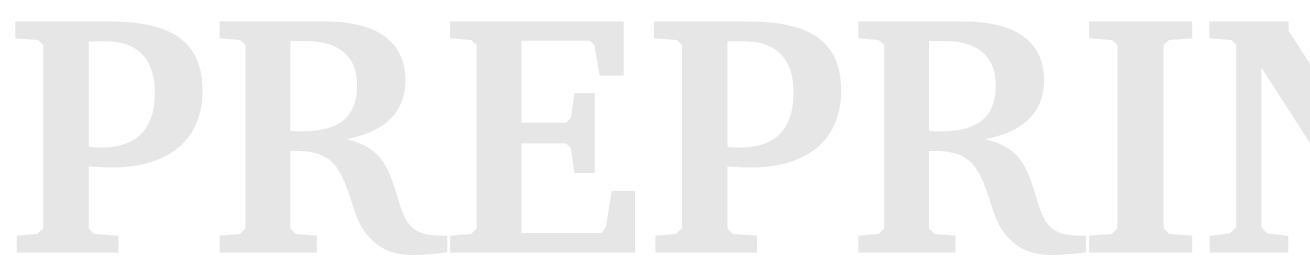

Corresponding author: Baird Langenbrunner, blangenb@uci .edu 


\begin{abstract}
Earth system models predict a zonal dipole of precipitation change over tropical South America, with decreases over the Amazon and increases over the Andes. Much of this has been attributed to the physiological response of the rainforest to elevated $\mathrm{CO}_{2}$, which describes a basin-wide reduction in stomatal conductance and transpiration. While robust in Earth system model experiments, details of the underlying atmospheric mechanismspecifically how it evolves in the context of land-atmosphere interaction and the diurnal cycle-are unresolved. We investigate this using idealized model simulations and find that within 24 hours of a $\mathrm{CO}_{2}$ increase, changes occur over the Amazon that engender synoptic timescale feedbacks. Decreased evapotranspiration from the rainforest throttles near-surface moisture, inducing a drier, warmer, and deeper boundary layer. Above this, enhanced turbulent diffusivity increases vapor in the lower free troposphere. Together, these processes reduce convective activity and cause immediate decreases in Amazon rainfall. Over the synoptic timescale, these changes leave behind lower tropospheric moisture, which is advected westward by the background jet and increases Andean precipitation. This produces a dipole of precipitation change consistent across global and regional models as well as parameterized and resolved convection, though details are sensitive to model topography and boundary layer formulation. The mechanism reported here stresses the importance of fast timescale processes affecting stability over a period of hours that can influence longer-term vegetation-climate interactions. These results help clarify the Amazon's physiological response to rising $\mathrm{CO}_{2}$ and provide insight into possible causes of historical model biases and end-of-century uncertainty in this region.
\end{abstract}

\title{
1 Introduction
}

The Amazon is the largest tropical forest on Earth, containing an estimated 25\% of global biodiversity and accounting for $15 \%$ of global photosynthesis [Field et al., 1998; Dirzo and Raven, 2003]. As atmospheric $\mathrm{CO}_{2}$ concentrations increase to levels not seen since at least the Pliocene [ $\sim 3$ million years before present, Tripati et al., 2009; Pagani et al., 2010], understanding how the region will respond to climate change is central to making long-term predictions for regional carbon and water cycles, and this knowledge will inform rainforest management practices in the twenty-first century.

Historically, precipitation that maintains the Amazonian hydrological cycle is tied to the seasonal migration of the intertropical convergence zone (ITCZ) and the low-level circulation associated with it, which changes position from zonal to northeasterly throughout the annual cycle and shapes the South American monsoon during the wet season [Vera et al., 2006]. In addition, precipitation recycling (i.e., the cascade of moisture through precipitation, evapotranspiration, and subsequent precipitation cycles) - especially during the dry season-is a critical source of moisture for the interior rainforest and is estimated to contribute 20-30\% of rainfall over the Amazon basin [Brubaker et al., 1993; Eltahir and Bras, 1994; Lee et al., 2005; Van der Ent et al., 2010; Zemp et al., 2014; Staal et al., 2018]. Canopy evapotranspiration is also influential in the dry-to-wet transition season, moistening the lower and middle atmosphere in the months leading up to the monsoon and priming the troposphere for deep convection [Wright et al., 2017].

Precipitation is therefore critical to rainforest health, but it is robustly predicted to decrease over the Amazon and increase over the Andes in realistic simulations of the twenty-first century from the Climate Model Intercomparison Project phase 5 [CMIP5, Taylor et al., 2012]. A significant fraction of this dipole of precipitation change is attributed to the physiological response of vegetation to atmospheric $\mathrm{CO}_{2}$ [Swann et al., 2016; Bonfils et al., 2017; Skinner et al., 2017; Kooperman et al., 2018; Richardson et al., 2018]. Stomatal resistance increases under elevated $\mathrm{CO}_{2}$, leading to a decrease in evapotranspiration and less water loss during photosynthesis [Field et al., 1995]. The immediate effect of this transpiration decrease is to dry out the boundary layer, and the feed- 
backs of this are strongest in tropical forest regions [Kooperman et al., 2018], where high initial leaf area limits the sensitivity of evapotranspiration to further increases in canopy biomass, and where boundary layer moisture is heavily dependent on canopy evapotranspiration. Developing a better understanding of how the Amazon rainforest will respond to increased atmospheric $\mathrm{CO}_{2}$, and the implications this will have for regional evapotranspiration and boundary layer moisture, is a key aspect of predicting future vegetation-climate interaction.

A number of studies has shed light on this physiological response, particularly at continental and global scales. The common approach in these experiments is to confine $\mathrm{CO}_{2}$ increases in an ESM to the land surface alone, which isolates this vegetation-driven feedback from the radiative effects of $\mathrm{CO}_{2}$ [e.g., Sellers et al., 1996; Betts et al., 2004; Pu and Dickinson, 2014]. A subset of eight modeling centers produced these experiments under CMIP5, permitting intermodel comparisons on how the physiological effect will influence temperature, precipitation, and drought [Swann et al., 2016; Lu et al., 2016; Lemordant et al., 2018; Skinner et al., 2017, 2018]. Only some of these studies, however, have explored the structure of changes within the Amazon specifically [e.g., Abe et al., 2015; Skinner et al., 2017; Richardson et al., 2018; Kooperman et al., 2018]. These papers focus on multidecadal to century-long timescales and attribute the wet Andes, dry Amazon dipole to an increase in the column-integrated export of moisture or moist static energy (MSE) from the Amazon lowlands toward the Andean cordillera [Skinner et al., 2017; Kooperman et al., 2018]. To date, no study has assessed the rapid evolution of the forest's response to $\mathrm{CO}_{2}$ as it develops in time.

Recently, Richardson et al. [2018] examined the Amazon physiological response in an ESM ensemble and attributed the precipitation decrease to a fast response distinct from long-term adjustments of global mean temperature. They calculate the relative contribution of terms in the surface energy budget and find that the re-partitioning of sensible and latent heat fluxes-amounting to an increase in the Bowen ratio (sensible heat divided by latent heat)—was the first-order cause of Amazon precipitation decreases. They find that this surface energy budget-driven response arises from thermodynamic changes to the structure of moisture in the atmosphere, independent of circulation. The fast aspect of the response in this paper is in reference to multidecadal climate model simulations with sea surface temperatures (SSTs) held fixed. Locating the physiological response within this window usefully rules out century-long feedbacks and helps tether Amazon precipitation decreases to local processes operating at the scale of the rainforest canopy.

However, a fast response defined this way still includes soil moisture and land-atmosphere feedbacks acting over several decades, and Richardson et al. [2018] employ column-integrated budgets that do not interrogate the vertical structure of the boundary layer or the role it plays in the physiological response, which Kooperman et al. [2018] show is important. This therefore leaves open questions about a faster process chain by which these precipitation anomalies initially develop-specifically the timescale over which they become evident and the land-atmosphere interactions or boundary layer feedbacks that accompany them. We answer several outstanding questions about this mechanism. First, does this Amazon precipitation change dipole exist in a higher resolution climate model, or is it an artifact of the $\sim 1-2^{\circ}$ resolution of ESMs in the CMIP5 archive? Second, if the signal is consistent across models and scales, how quickly do changes develop, and how do they evolve? Stomatal closure is a fast process-operating on a minutes-to-hours timescale relevant to photosynthesis - so if precipitation changes rely mostly on vegetative controls, one might expect the Amazon forest component of the precipitation change dipole to set up quickly. Third, how are fast processes that influence deep convection over a period of hours mechanistically tied to larger-scale changes in circulation and moisture transport over a period of days to weeks?

In the analysis below, we show that the $\mathrm{CO}_{2}$ response is present in a regional climate model and that it develops robustly within the first few days of a $\mathrm{CO}_{2}$ increase, inde- 
pendent of whether convection is parameterized or explicitly resolved. Important changes emerge within the first 24 hours that prime the atmosphere above the rainforest for a precipitation decrease, with an Andes increase developing later over the synoptic ( 10-day) timescale. Below, we focus first on the synoptic response and then discuss the initial stages within the first simulation day. We find that first-day changes arise from enhanced mixing in the lower free troposphere, where local eddy diffusivity causes vertical shifts in cloud fraction and moisture flux that coincide with a generally more stable atmosphere and reduced likelihood for deep convection. We discuss the potential application of this mechanism to better frame and understand uncertainty in the Amazon climate in ESMs.

\section{Description of model simulations}

We generated five sets of simulations for this study, all of which were integrated in a perpetual solar equinox setup. Baseline simulations consisted of 50-km Weather Research and Forecasting version 3.9 (WRF 3.9) model runs with fixed sea surface temperatures (SSTs). The second set of simulations included sensitivity tests done with alternative boundary layer schemes. A third set involved convection-resolving WRF simulations integrated on a nested domain at 50-, 10-, and 2-km resolution, with resolved convection on the smallest domain. Two final sets were created using the Community Earth System Model version 1.2 (CESM 1.2) integrated at $2^{\circ}$ resolution with a fully interactive ocean. The first of these was a 10-member initial condition ensemble run for 30 days, and the second was a single 10-year simulation.

For each set of simulations, control and physiological forcing cases were created. In control runs $\left(\mathrm{CO}_{2}\right.$,cont $)$, the $\mathrm{CO}_{2}$ concentration was set to $400 \mathrm{ppm}$ in the atmosphere and land model. For physiological forcing runs $\left(\mathrm{CO}_{2}\right.$,phys $), \mathrm{CO}_{2}$ concentration was set to a constant $1000 \mathrm{ppm}$ in the land model and $400 \mathrm{ppm}$ in the atmosphere. These simulations are similar to the physiological forcing experiments in the CMIP5 archive [e.g., Taylor et al., 2012, specifically "esmFdbk1"], but in this case, $\mathrm{CO}_{2}$ was increased immediately and held constant, rather than being increased $1 \%$ year $^{-1}$ as in the CMIP5 protocol. Our use of an abrupt $\mathrm{CO}_{2}$ increase helps assess the rapid aspects of the physiological response that are independent of soil moisture feedbacks, which are unavoidable in gradual ramp-up experiments. For more information on our setup, see the text below and Table S1.

\subsection{WRF 50-km baseline runs}

The baseline runs were done with a 50-km WRF domain symmetric about the equator (see full domain in Fig. 1c) with 30 vertical model levels and a hybrid vertical coordinate. 6-hour data at $2.5^{\circ}$ resolution from the National Center for Environment Prediction version 2 (NCEP2) reanalysis [Kanamitsu et al., 2002] were used to create a set of mean lateral boundary conditions during 1979-2016.

To mimic equinox boundary conditions, we averaged the forcing data around the March and September equinoxes (February-April and August-October) for all years 19792016. These fields were then used to force WRF at 00:00, 06:00, 12:00, and 18:00 Coordinated Universal Time (UTC), repeated as a 24-hour cycle for 10 days. Solar forcing in the radiation scheme was set to equinox conditions with an Earth-Sun distance of 1 astronomical unit, the mean annual value. This approach was chosen to minimize noise from seasonality and internal atmospheric variability in order to reveal the physiological response as cleanly as possible, while still benefiting from the higher resolution of WRF.

$\mathrm{CO}_{2 \text {,cont }}$ and $\mathrm{CO}_{2, \text { phys }}$ forcings were integrated 10 separate times for 10 days each, with stochastic perturbations added to the boundary conditions at every time step to generate an initial condition ensemble [akin to a WRF forecast ensemble; Berner et al., 2011; Duda et al., 2016]. Output was saved at hourly intervals. 
(a) land use categories and elevation

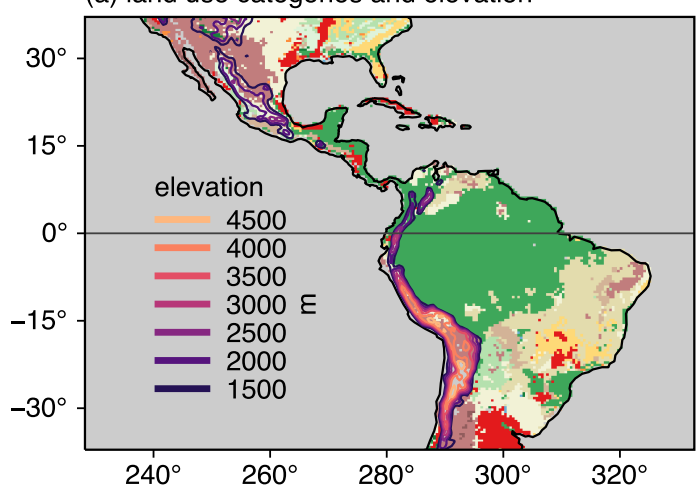

(b) obs. precip. and $850 \mathrm{hPa}$ wind
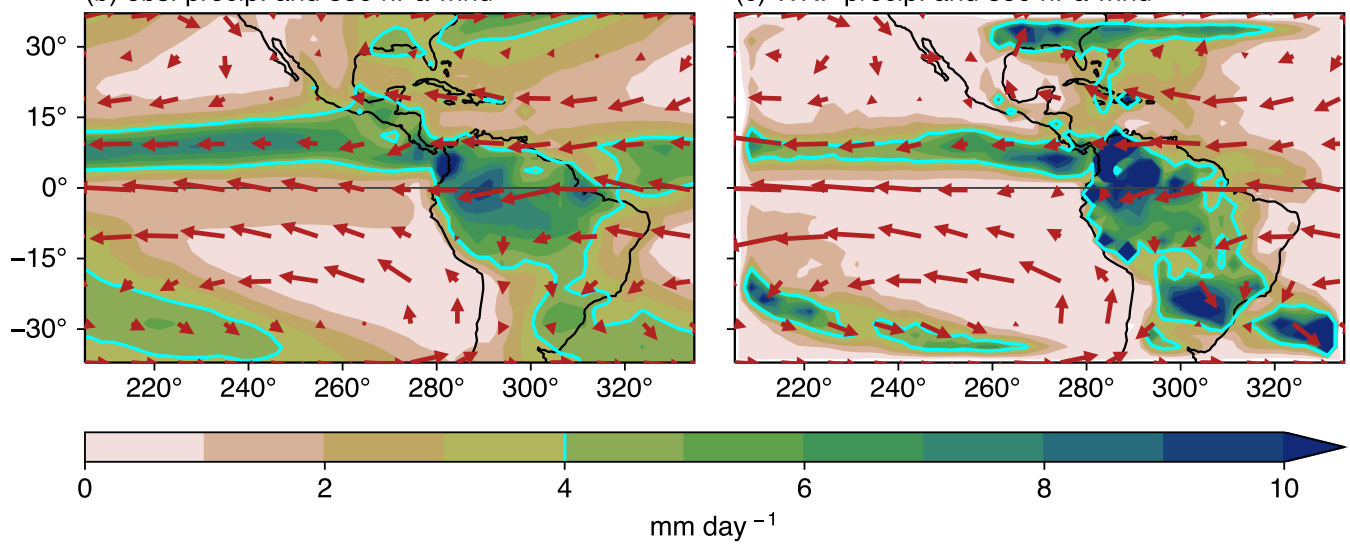

Figure 1. (a) Land use categories and elevation for WRF domain. (b) Observed equinox precipitation and $850 \mathrm{hPa}$ wind climatologies during 1979-2017, taken from GPCP and NCEP2. (c) 10-day mean precipitation and $850 \mathrm{hPa}$ winds for equinox conditions from the ensemble mean of $\mathrm{CO}_{2}$, cont WRF simulations. WRF domain is shown in $(b-c)$. Equinox conditions refer to the combined average of February-April and August-October periods, centering on the March and September equinoxes.

The land cover classification and elevation for the WRF domain are shown in Fig. 1a, where the broad region in South America corresponding to "evergreen broadleaf forest" approximates the Amazon rainforest. The observed precipitation and low-level jet climatology during the mean equinox season are shown in Fig. 1b during 1979-2016, depicting a northwest-to-southeast orientation of the ITCZ and large precipitation gradients moving along the low-level jet path. The 10-day mean precipitation and low-level jet winds of the $\mathrm{CO}_{2 \text {,cont }}$ runs are shown in Fig. 1c. Compared to observations and reanalyses, the low-level winds and general structure of deep convective rainfall appear to be reasonably well simulated, despite the large differences in the length of the averaging period (compare Figs. $1 \mathrm{~b}$ and $1 \mathrm{c})$.

The physics parameterizations chosen for these simulations were based on the "tropical physics" suite available in WRF. The default settings include the new Tiedtke mass flux scheme for cumulus convection [Tiedtke, 1989; Zhang et al., 2011; Bechtold et al., 2004, 2008, 2014], the rapid radiative transfer model for longwave and shortwave radiation schemes [Iacono et al., 2008], the Yonsei University (YSU) scheme for boundary layer physics [Hong et al., 2006], and the single-moment 6-class scheme for microphysics [Hong and Lim, 2006]. Instead of the default land model, we chose to use the Noah land surface model with multiparameterization options [Noah-MP; Niu et al., 2011; Yang et al., 2011]. 
Important aspects of the Noah-MP and YSU schemes are discussed in the Supporting Information.

\subsection{WRF boundary layer sensitivity runs}

To test the sensitivity of our simulations to boundary layer formulation, we performed additional 50-km integrations for $\mathrm{CO}_{2 \text {,cont }}$ and $\mathrm{CO}_{2}$,phys each for 10 days with an identical setup to those above but with five additional boundary layer schemes in addition to YSU. We used the Mellor-Yamada Nakanishi Niino level 3 (MYNN3) scheme [Nakanishi and Niino, 2006, 2009], the Asymmetric Convection Model 2 (ACM2) scheme [Pleim, 2007a,b], the University of Washington (UW) scheme [Bretherton and Park, 2009], the total energy-mass flux (TEMF) scheme [Angevine et al., 2010], and the Mellor-YamadaJanjic (MYJ) scheme [Janjić, 1994].

\subsection{Convection-resolving WRF runs}

To test the sensitivity of our results to convective parameterization, we ran an additional WRF simulation in a nested, two-way domain setup at 50-, 10-, and 2-km resolution, chosen so that the smallest domain spans the region where largest precipitation changes were seen in preliminary $50-\mathrm{km}$ runs (see Fig. S1). The boundary conditions at the coarsest domain were identical to the 50-km setup above, and 30 vertical levels were also used here. The only difference in model physics is that the deep convection scheme was turned off for the $2-\mathrm{km}$ domain to allow for resolved convection and precipitation.

\subsection{Earth system model runs}

To compare our results to an ESM, we used CESM 1.2 with the Community Land Model version 4.0 [CLM4; Oleson et al., 2010], the Community Atmosphere Model version 5.0 [CAM5; Neale et al., 2010], and a fully interactive ocean run at $2^{\circ}$ resolution on a finite volume grid. The first type of integration was a 10 -member initial condition ensemble of 30-day $\mathrm{CO}_{2 \text {, cont }}$ and $\mathrm{CO}_{2 \text {,phys }}$ runs. A second set of $\mathrm{CO}_{2 \text {, cont }}$ and $\mathrm{CO}_{2 \text {, phys simu- }}$ lations was completed for 10 years in order to compare CESM's decadal scale physiological response. As with the WRF simulations, these were integrated under perpetual equinox conditions.

\section{Synoptic timescale response}

The 50-km WRF simulations served as the primary data set analyzed in this study and are compared to others in section 3.2. Overall, we find that the physiological response exhibits an evolution that begins with a very fast adjustment (within the first diurnal cycle) as well as a slower synoptic timescale response. With this dichotomy in mind, we first discuss results that develop over the synoptic scale, which align with previous results from simulations of the physiological response over long timescales, and we return later to the first day, which offers an especially noise-free view of important forest-atmosphere interactions and their causality.

\subsection{Surface and column-integrated changes}

Figure 2 shows the 10-day mean physiological response for important fields in the WRF baseline simulations. Focusing first on precipitation change (Fig. 2a), decreases are evident over a broad region of the eastern Amazon rainforest, particularly along the northeastern coast of South America in the Guianas region, where reductions exceed 25\% of the control simulation. Precipitation increases of approximately $20 \%$ occur along the mountainous Andes to the west, in regions that are narrower and aligned with topography. Altogether, the largest precipitation anomalies occur along the equator between $10^{\circ} \mathrm{S}$ and 
(a) $\Delta$ precipitation

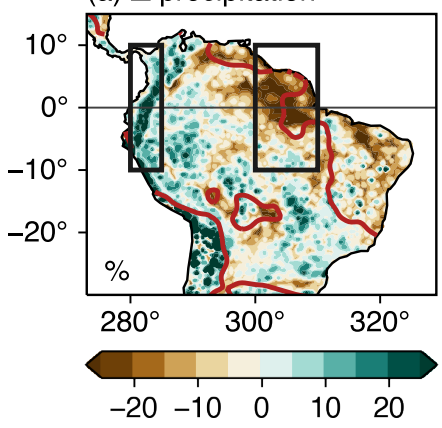

(d) $\Delta 2 m$ air temperature

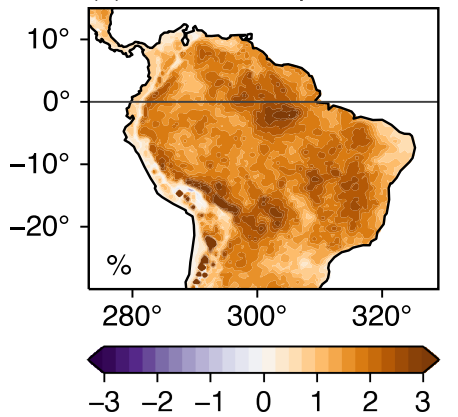

(b) $\Delta$ transpiration

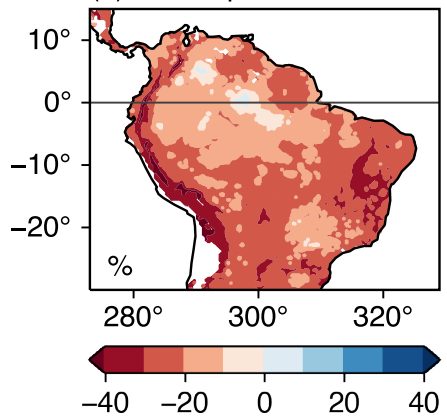

(e) $\Delta$ boundary layer ht.

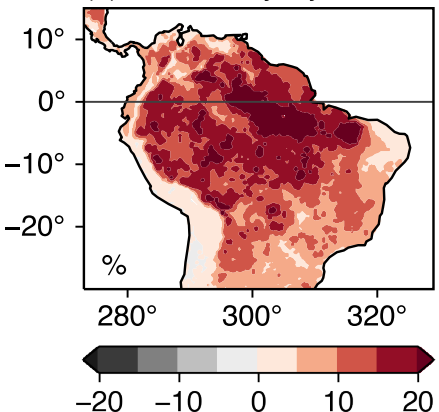

(c) $\Delta$ latent cooling

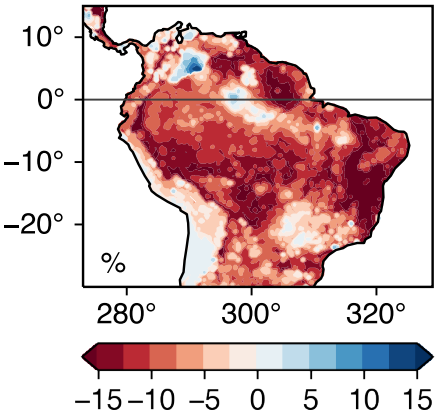

(f) $\Delta$ column water vapor

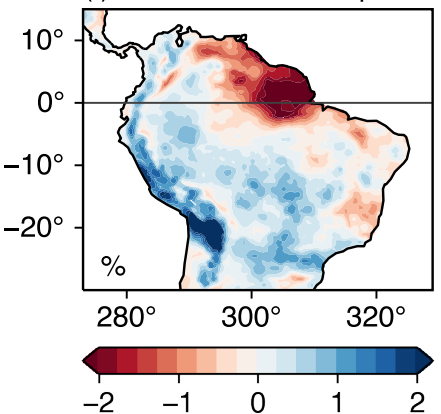

Figure 2. Ensemble mean differences during days 2-10. Delta $(\Delta)$ represents changes for physiological minus control $\mathrm{CO}_{2}$ simulations $\left(\mathrm{CO}_{2}\right.$,phys $-\mathrm{CO}_{2}$, cont $)$. Values are shown as a percent of $\mathrm{CO}_{2 \text {, cont }}$. Boxes in (a) show the Andes and Amazon regions over which averages are taken in subsequent figures. The absolute change and control fields are shown in Figs. S2 and S3. Red lines in (a) show the $4 \mathrm{~mm}^{-1}$ precipitation $^{-1}$ contours in $\mathrm{CO}_{2}$, cont .
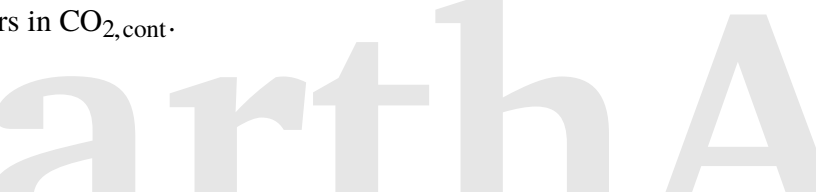

$10^{\circ} \mathrm{N}$, likely due to a combination of the equinox setup and the physical location of the tropical forest vegetation (Fig. 1a). For reference, climatological and absolute changes are shown in Figs. S2 and S3.

Other fields change in ways that confirm expectations. Canopy transpiration (Fig. 2b) decreases everywhere there is vegetation. This decrease is important over the Amazon basin, where precipitation recycling via evapotranspiration is important [e.g., Zemp et al., 2014; Staal et al., 2018] and where decreased moisture flux to the atmosphere will affect the moisture supply available to convection and precipitation. This decrease in transpiration is associated with a diminished latent cooling at the surface (Fig. 2c) and increase in surface air temperature (Fig. 2d), implying increased sensible heat flux and an increased Bowen ratio.

These aspects of the surface energy budget lead to a warmer and deeper mean boundary layer (Fig. 2e). Associated changes in the vertical structure of MSE play a fundamental role at the synoptic timescale, as discussed in section 4. Column-integrated water vapor (Fig. 2f) decreases primarily over the region with the largest precipitation decreases, though with a wider footprint than precipitation change itself. This implies that changes in column moisture are a helpful proxy for where broad shifts in precipitation occur, qualitatively confirming well-known aspects of the moisture-precipitation relationship [e.g., Bretherton et al., 2004; Holloway and Neelin, 2009; Schiro et al., 2016]. That the patterns of precipitation and column water vapor change do not resemble those of transpiration and latent cooling implies that there is a distinct rearrangement of moisture transport. 


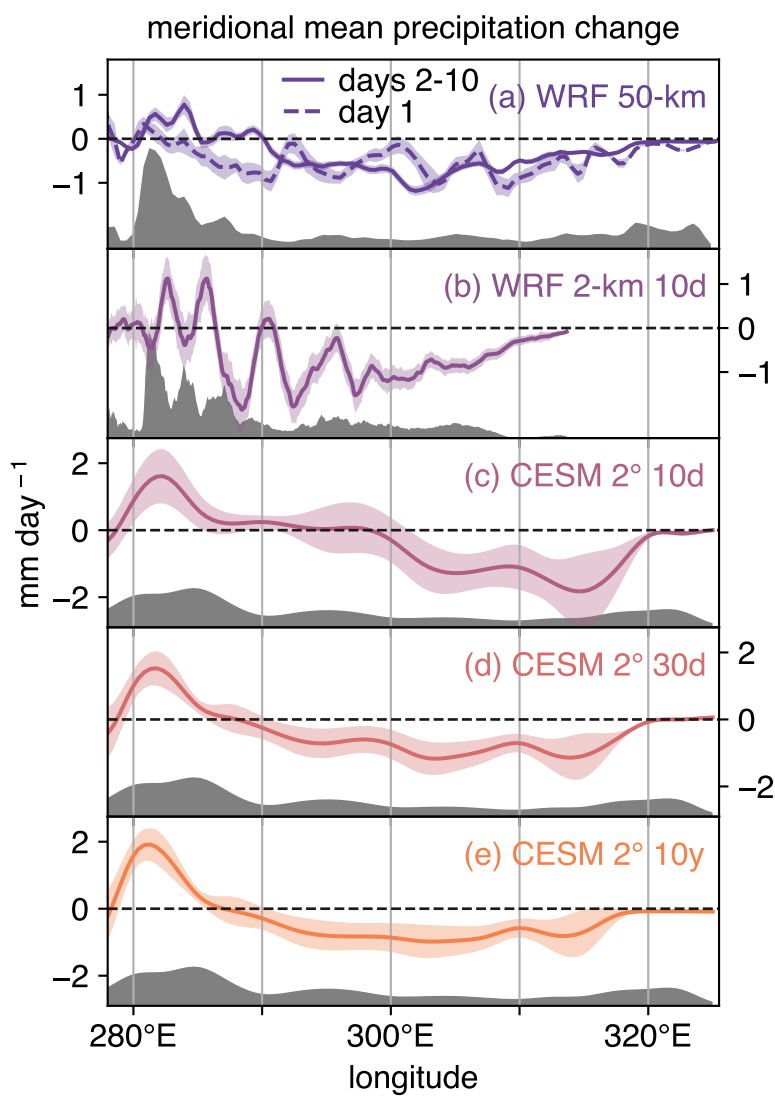

Figure 3. Meridional mean precipitation change in the physiological response $\left(\mathrm{CO}_{2}\right.$, phys $\left.-\mathrm{CO}_{2 \text {, cont }}\right)$ across models, resolution, and timescales. (a) 10-member ensemble mean for first day (hours 06:00-20:00, neglecting the first 10 hours of spinup) and days 2-10 in the 50-km WRF simulations. (b) 1-member 10-day mean for 2-km WRF simulation. (c) 10-member ensemble mean for first 10 days of CESM integrations. (d) Same as (c) but for first 30 days. (e) 1-member 10-year mean for CESM simulation. All averages are taken for land-only grid points between $10^{\circ} \mathrm{S}$ and $10^{\circ} \mathrm{N}$, except for the WRF 2-km run, which has a northward-shifted domain (see Fig. S1). Error bars show 95\% confidence interval for changes, calculated as $\pm 1.96 \times$ s.e. (where the standard error s.e. $=\sigma / \sqrt{N} ; \sigma=$ the standard deviation of the precipitation change across latitude; $N=$ the number of latitude points). Latitudinal mean model topography at its native model resolution is shown on each plot as light gray shading, all scaled relative to the 2-km topography in (b), which has a maximum average peak of $\sim 1.83 \mathrm{~km}$ near $282^{\circ} \mathrm{E}$.
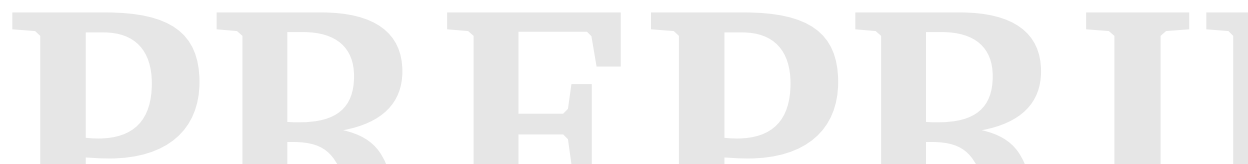

\subsection{Comparing across models, convective formulation, and timescale}

This stomatal-driven dry Amazon, wet Andes precipitation change dipole has been confirmed across multiple ESMs [e.g., Swann et al., 2016; Richardson et al., 2018; Kooperman et al., 2018], and Fig. 2 indicates that it appears in a regional climate model, though it remains an open question whether the response is tied to a specific timescale or model resolution, and these aspects are compared in Fig. 3. Figure 3a displays the WRF 50-km changes for the synoptic timescale (days 2-10) and the first diurnal cycle. The solid line depicts the mean change seen in Fig. 2a, with decreases over the Amazon lowlands and increases over the higher Andean topography. The dashed line gives important information about day 1 not visible in the synoptic mean plots: precipitation decreases immediately 
within the first diurnal cycle throughout the Amazon basin, with a magnitude comparable to the full synoptic response.

The convection-resolving 2-km WRF integration shows a noisier pattern of change, but decreases over the Amazon basin and increases over the Andes are still clear over a 10-day mean (Fig. 3b). The variation with longitude is likely due to the more highly resolved topography and a smaller domain (Fig. S1), as well as the fact that the $2-\mathrm{km}$ run (due to its computational expense) only has a single realization. Still, this result suggests that the physiological precipitation response is not an artifact of parameterized deep convection.

Figures 3c-e show CESM results for a 10-day, 30-day, and 10-year mean. Across this large range of timescales, the physiological response dipole is consistent: decreases are seen throughout the Amazon basin, and increases are aligned closely with the CESM's Andean topography. The precise magnitude and location of the maximum changes vary within each model and among all simulations, but the broad details are stable, suggesting that the physiological response of the Amazon rainforest is a result of fundamental moist processes that can be captured in consistent ways across a range of model time and space scales.

More broadly, these results highlight that the mechanism leading to a drier Amazon and wetter Andes pattern is fast and does not initially rely on slower feedbacks related to soil moisture change, which would take longer than days or weeks to develop. In addition, the primary precipitation increases in the $50-\mathrm{km}$ simulations occur in concentrated regions over the Andes, implying that local orographic dynamics are important to the exact spatial pattern of the response. While this aspect is less clear from CMIP5 model experiments, the primary mechanism still operates at a two- to fourfold coarser resolution relative to the WRF simulations, even with comparatively under-resolved topography.

\subsection{Diurnal cycle of precipitation change}

Over the full 10-day WRF ensemble, a distinct diurnal cycle is present in both the control precipitation and the physiological response. Figure 4 gives both a summary of precipitation change for the Andes and Amazon regions and unfolds the diurnal cycle time series. Here, "Andes" refers to grid points located above $1.5 \mathrm{~km}$ elevation. In the physiological response, Andean precipitation increases by about $10 \%$, while the Amazon region experiences a $\sim 17 \%$ precipitation decrease. In both cases, the percent contributions from nighttime and daytime precipitation remain fairly consistent.

Figures $4 \mathrm{~b}-\mathrm{e}$ show the precipitation time series on which Fig. 4a is based, plotted over all 10 simulation days. Vertical grid lines are shown at 15:00 local time to highlight mid-afternoon convective activity. Over both the Amazon and Andes, precipitation peaks can be seen at this hour, with secondary peaks in nighttime precipitation. Over the Andes (Fig. 4c), precipitation increases on the first two days are confined to the afternoon peak of convection, but after a few days of adjustment, anomalies steadily increase throughout the full diurnal cycle. Over the Amazon (Fig. 4e), precipitation decreases occur within the first afternoon during the peak of convective activity (seen also in Fig. 3a), with immediate secondary decreases during nighttime rainfall, and this pattern remains consistent through the simulation with less synoptic amplification than the Andes response.

\subsection{Vertical structure of afternoon changes in moisture, clouds, and temperature}

To better understand the changes occurring to mid-afternoon convection over the Amazon seen in Fig. 4, low-level moisture, cloud fraction, and temperature changes are shown at 15:00 during days 2-10 in Fig. 5. The boundary layer heights for $\mathrm{CO}_{2 \text {, cont }}$ and $\mathrm{CO}_{2 \text {,phys }}$ highlight an increase in the mixed layer depth of nearly $200 \mathrm{~m}(\sim 50 \mathrm{hPa})$ in the physiological response. In addition, this boundary layer height serves as the boundary of a 
(a) Mean regional precip.

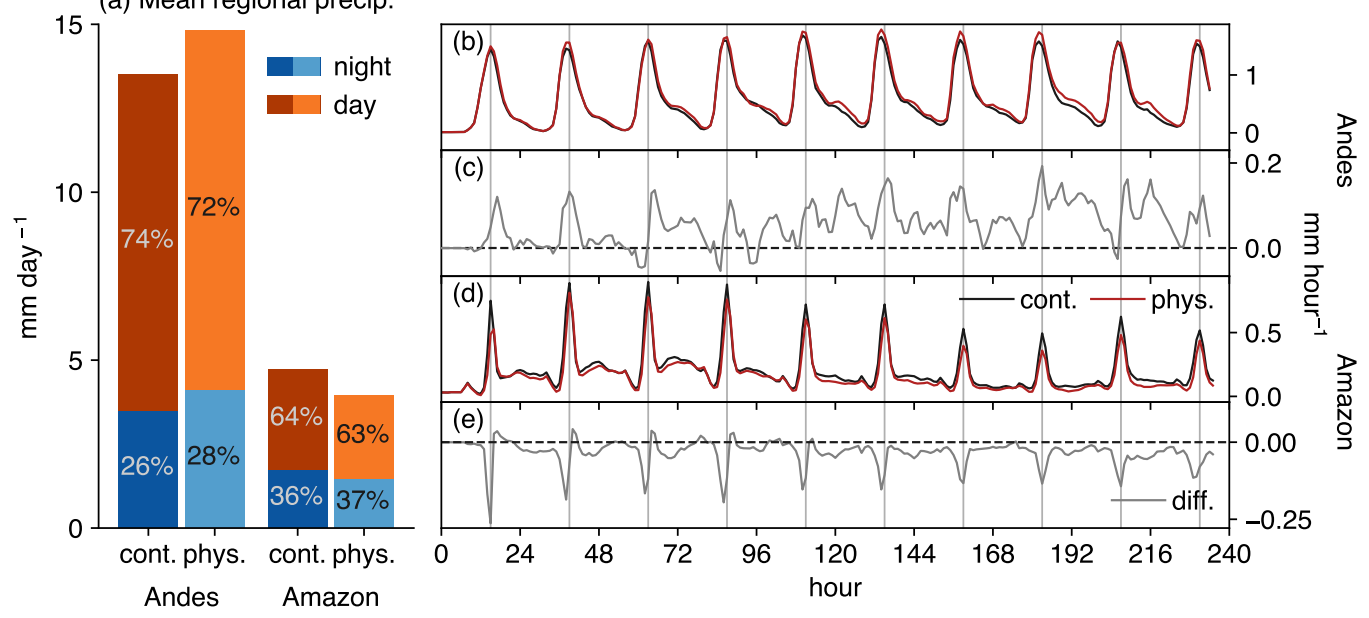

Figure 4. Ensemble mean precipitation in the $\mathrm{CO}_{2}$, cont and $\mathrm{CO}_{2}$,phys runs, calculated over regions in Fig. 2a. "Andes" in this case represents all grid points within that region at an altitude greater than $1.5 \mathrm{~km}$. (a) Area-mean precipitation for the Andes and Amazon regions, broken into the contributions during daytime and nighttime periods. Daytime represents 08:00-20:00, and nighttime spans 20:00-08:00. Percentages in the bars show the percent contribution of each time period to the total. (b) Control and physiological time series for the Andes region. (c) Difference for $\mathrm{CO}_{2}$,phys $-\mathrm{CO}_{2}$, cont . (d) Control and physiological response for the Amazon region. (e) Difference for $\mathrm{CO}_{2}$,phys $-\mathrm{CO}_{2}$, cont in the Amazon region. 15:00 is shown as vertical grid lines in (b-e). Hours are shown as local time starting from midnight on day 1 of the simulation. For the Andes, local time is UTC-5, and for the Amazon, local time is UTC-4 (i.e., Andean time series have been shifted one hour earlier to match local afternoon).

moisture change dipole (Fig. 5a), with large decreases in the lower $1.5 \mathrm{~km}$ due to declines in evapotranspiration.

It is not immediately obvious why changes in the surface energy budget, driven by elevated $\mathrm{CO}_{2}$, should sustain more vapor and low-level clouds in the free troposphere just above the boundary layer, yet this is clearly the case. Consistent with the strongest moisture increases above $\sim 1.5 \mathrm{~km}$, cloud fraction shifts higher into the atmosphere in Fig. $5 \mathrm{~b}$. The zero line for cloud fraction change is above that of moisture, suggesting a higher lifting condensation level (LCL). The cloud fraction differences themselves are more vertically confined, though the largest magnitude increases in moisture in Fig. 5a coincide with the axis of maximum cloud fraction increase in Fig. 5b. All of these changes result from a warmer and drier boundary layer, with temperature increases of $1{ }^{\circ} \mathrm{C}$ or more throughout the lowest $1.5 \mathrm{~km}$ (Fig. 5c). Mid-afternoon zonal wind anomalies show that the dynamical components of this response are relatively weak, with a minor enhancement of the easterly boundary layer flow and a slight deceleration of the easterly jet above (Fig. 5c).

Equivalent plots for the full atmosphere are shown in Fig. S4. The moisture and temperature changes are confined to the lowest few $\mathrm{km}$ of the atmosphere, but there is a clear decrease in deep convective clouds (in the 12-16 km layer), implying decreased convective activity discussed below. Vertical velocities averaged over the full diurnal cycle show anomalous ascent over the Andes and descent over the Amazon basin, confined to the longitudes between $10^{\circ} \mathrm{N}$ and $10^{\circ} \mathrm{S}$ with the largest precipitation decreases in Fig. $2 \mathrm{a}$.

To gain insight into the mid-afternoon Amazon precipitation decrease, Fig. 6 shows a skew-T diagram for temperature profiles over the Amazon region in Fig. 2a. Temper- 


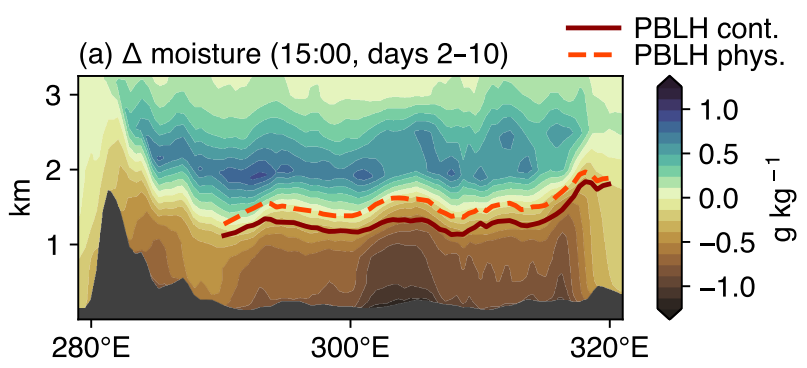

(b) $\Delta$ cloud fraction (15:00, days $2-10)$

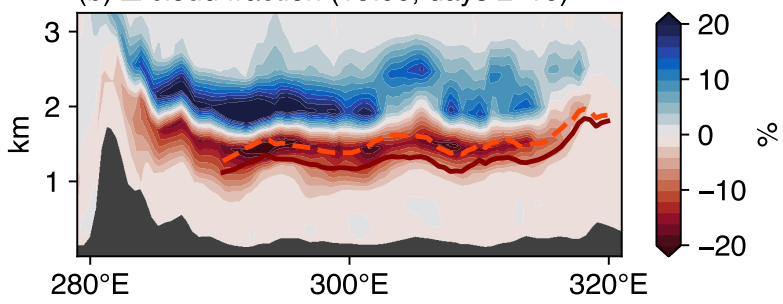

(c) $\Delta$ temperature $(15: 00$, days $2-10) \longrightarrow 1 \mathrm{~m} \mathrm{~s}^{-1}$

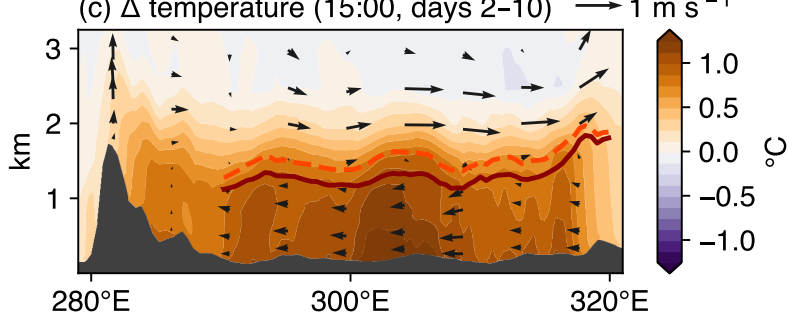

Figure 5. Ensemble mean physiological response $\left(\mathrm{CO}_{2, \text { phys }}-\mathrm{CO}_{2 \text {, cont }}\right)$ in atmospheric moisture, clouds, and temperature during hour 15:00 for days 2-10. Times were calculated for central South American local time $\left(\sim 300^{\circ} \mathrm{E}\right)$ at $\mathrm{UTC}-4$. Plots show latitudinal mean changes between $10^{\circ} \mathrm{S}$ and $10^{\circ} \mathrm{N}$ for (a) moisture, (b) cloud fraction, and (c) temperature and $\mathrm{u}-\mathrm{w}$ winds. To emphasize vertical velocity, $w$ is scaled by a factor of 100 (i.e., $\mathrm{cm} \mathrm{s}^{-1}$ ). The planetary boundary layer height (PBLH) at hour 14:00, as diagnosed by WRF, is shown as a dark solid and light dashed red line. Ocean grid points have been masked, so that contours represent changes over land only.

ature and calculated parcel profiles are drawn for the $\mathrm{CO}_{2}$,phys and $\mathrm{CO}_{2}$, phys runs, along with calculated convective available potential energy (CAPE) and convective inhibition (CIN) between the surface and $100 \mathrm{hPa}$. Aspects of the physiological response shown in Fig. 4 are also visible from this perspective: the $\mathrm{CO}_{2}$,phys profile shows a drier atmosphere, indicated by the lower dew point temperature $\left(T_{d}\right)$ between the surface and 850 $\mathrm{hPa}$, and a warmer environmental temperature $\left(\mathrm{T}_{\text {env }}\right)$ extending up to nearly $800 \mathrm{hPa}$.

These changes have opposing effects on the calculated parcel profile and its associated CAPE. A warmer boundary layer $\left(\mathrm{T}_{\mathrm{env}}\right)$ —all else equal—would cause a parcel to ascend on a warmer dry (and moist) adiabat, acting to increase CAPE. Yet decreased boundary layer moisture, holding environmental temperature constant, would reduce $\mathrm{T}_{\mathrm{d}}$ and CAPE. While both of these changes independently lead to a higher LCL and level of free convection (LFC), there is an overall decrease in CAPE of approximately $350 \mathrm{~J}$ $\mathrm{kg}^{-1}$, implying that the boundary layer moisture decrease is dominating the temperature effect in regulating the potential buoyancy of deep updrafts in these simulations. While these changes can appear modest at the scale of the full atmosphere, the boundary layer is particularly important for initiating deep convection in the Tiedtke convection scheme, which relies on consumption of CAPE over a specified timescale for numerical closure. 


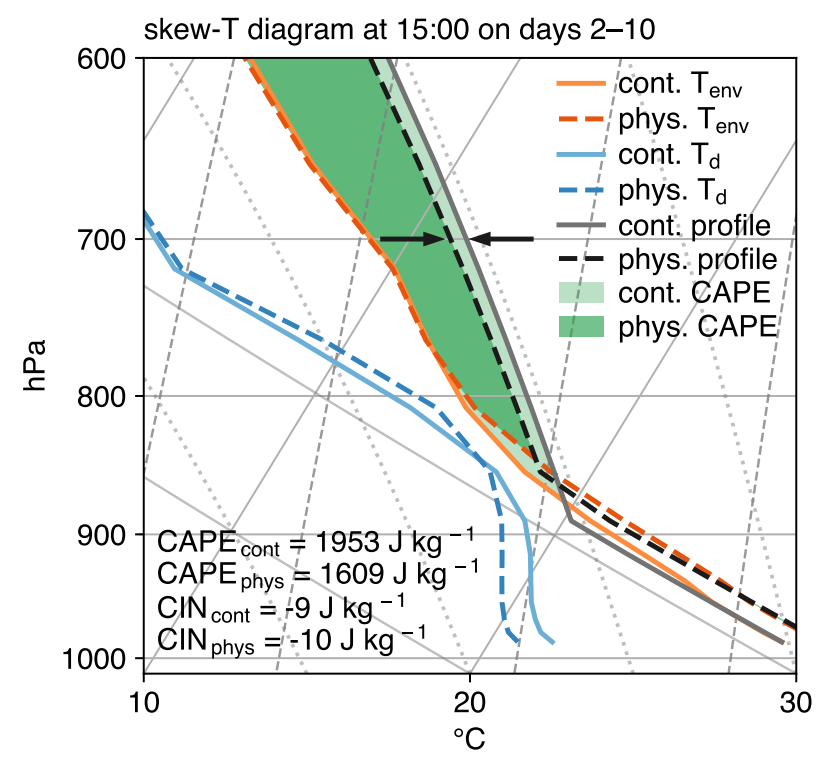

Figure 6. Ensemble mean skew-T diagram for $\mathrm{CO}_{2}$, cont and $\mathrm{CO}_{2 \text {, phys }}$ at 15:00 averaged during days 2-10. Orange lines show environmental temperature $\left(\mathrm{T}_{\mathrm{env}}\right)$, blue lines show dew point temperature $\left(\mathrm{T}_{\mathrm{d}}\right)$, and black and gray lines show the calculated parcel profile. Convective available potential energy (CAPE) is shown as a shaded region for $\mathrm{CO}_{2}$,cont (light green) and $\mathrm{CO}_{2}$,phys (dark green). Profiles are shown for land-only grid points over the Amazon region shown in a box in Fig. 2a. Black arrows are included to emphasize differences in $\mathrm{T}_{\mathrm{env}}$ and CAPE between the simulations. Calculations of CAPE and convective inhibition (CIN) are included for a parcel following the given profiles from the surface up to $100 \mathrm{hPa}$.

We therefore suspect that this decrease in CAPE, arising from warming and especially drying in the lowest $2 \mathrm{~km}$ of the atmosphere, is a primary driver of precipitation decreases over the Amazon, as it would act to throttle the overall amount of deep convective activity in the model. These LCL and LFC changes and a zonal precipitation dipole have been noted in studies of the Amazon during studies of paleoclimate and future change [Pinto et al., 2009].

Further aloft, $\mathrm{T}_{\mathrm{env}}$ and $\mathrm{T}_{\mathrm{d}}$ between the $\mathrm{CO}_{2 \text {,cont }}$ and $\mathrm{CO}_{2 \text {,phys }}$ simulations are indistinguishable. This is consistent with the expectation that the tropical atmosphere in both simulations would be constrained by weak temperature gradient theory-that horizontal temperature differences are small in the tropics, and that owing to the smallness of the Coriolis parameter, any perturbations that form are quickly eliminated by internal gravity wave adjustments [e.g., Sobel et al., 2001].

\subsection{The low-level jet as a moisture bridge}

To see the time evolution of these anomalies and how the Andean precipitation increase sets up, Fig. 7 shows time-longitude plots of above-boundary-layer moisture and precipitation. The evolution of moisture in the 900-700 hPa layer is shown in Fig. 7a (corresponding approximately to the $2-3 \mathrm{~km}$ layer in Fig. 5 that experiences the strongest increases). When perturbations are positive above the boundary layer and negative within it, precipitation decreases immediately (Fig. 7b). This is followed by scattered precipitation increases that occur in the first diurnal cycle. As seen in Fig. 3a, however, these anomalies still show a negative overall change during day 1, implying a decrease in precipitation efficiency and an overall reduction in deep convection. 
(a) $\Delta$ moisture $(900-700 \mathrm{hPa}$ layer $)$

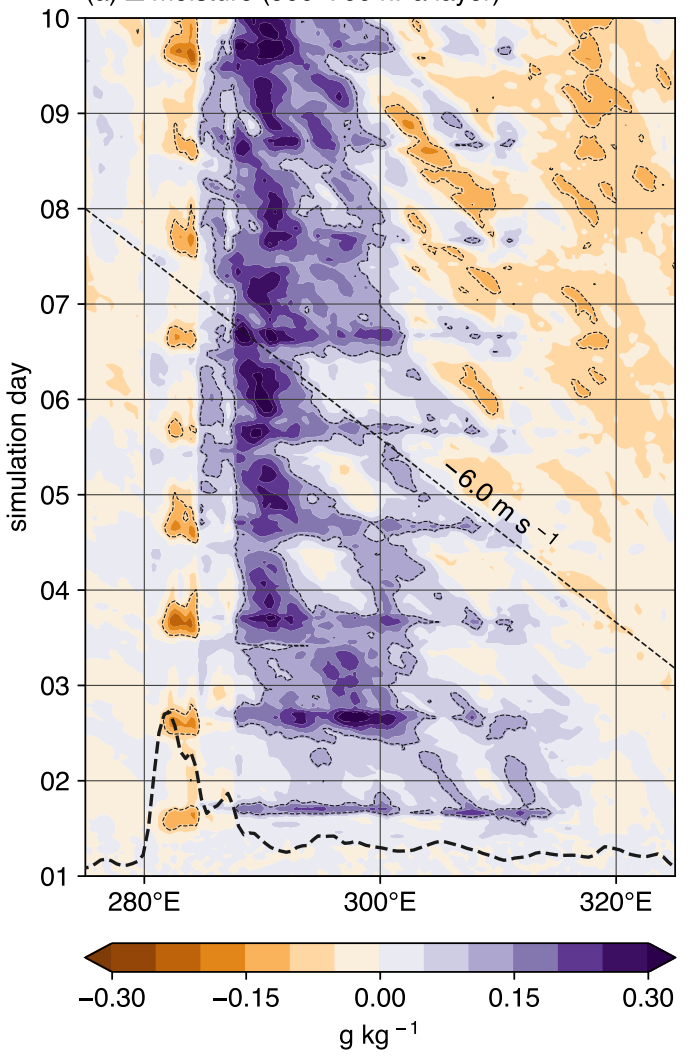

(b) $\Delta$ hourly precipitation

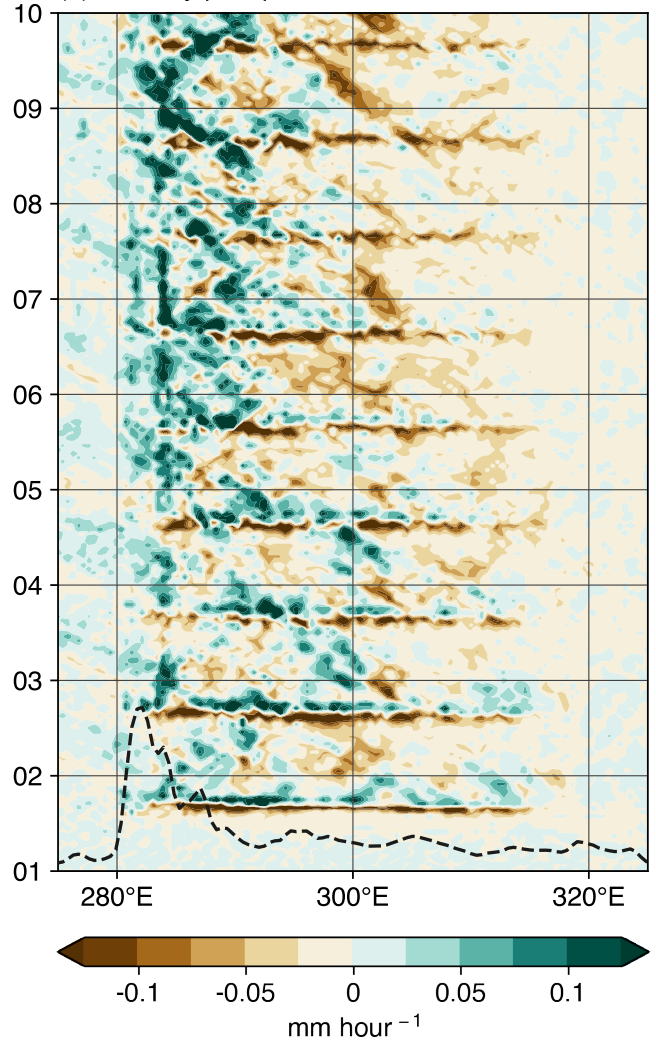

Figure 7. Time-longitude diagrams of the evolution of (a) moisture in the 900-700 hPa layer and (b) hourly precipitation anomalies for the ensemble mean of the $\mathrm{CO}_{2}$,phys $-\mathrm{CO}_{2}$, cont simulations. These plots are shown for meridional mean anomalies between $10^{\circ} \mathrm{S}$ and $10^{\circ} \mathrm{N}$. Sloped line in (a) shows the approximate mean zonal velocity in $290^{\circ} \mathrm{E}-310^{\circ} \mathrm{E}$. Dashed contour lines are drawn in (a) for $\pm 0.1 \mathrm{~g} \mathrm{~kg}^{-1}$ to emphasize advective velocity. Dashed line at bottom of each plot gives a schematic view of mean topography throughout the domain. Negative moisture anomalies occur over the Andes in (a) because this falls within the boundary layer, though these anomalies are positive above $\sim 3 \mathrm{~km}$.

As the simulation evolves, beginning at approximately day 6, positive anomalies in above-boundary-layer moisture turn to decreases east of $300^{\circ} \mathrm{E}$ (Fig. 7a). As this happens, precipitation anomalies develop into consistently negative changes over the Amazon and positive changes over the Andes (Fig. 7b), and the classical physiological response becomes apparent. The dashed straight line in Fig. 7a denotes the approximate zonal wind velocity in the 900-700 $\mathrm{hPa}$ layer for $\mathrm{CO}_{2}$, cont - a proxy for the South American low-level jet. The nearly parallel orientation of moisture anomaly contours relative to this velocity line implies that there is a westward advection of moisture by the low-level jet from the Amazon basin toward the Andes. The positive anomalies developing above the boundary layer in the first few days of the simulation, combined with westward jet advection, are crucial aspects of the mechanics that bridge the local precipitation response over the Amazon to the nonlocal increase over the Andes at the synoptic timescale, and the presence of this advection in ESMs at longer timescales has been noted in previous work [Skinner et al., 2017; Richardson et al., 2018; Kooperman et al., 2018]. 


\section{The first diurnal cycle and originating processes}

\subsection{Fast moisture and cloud response}

Together, these various glimpses into the physiological response-and in particular the time evolution of anomalies in Fig. 7-provide evidence that it begins locally as a decrease in precipitation over the Amazon basin, and that the subsequent Andean precipitation increase relies on the advective timescale of the low-level jet to transport residual lower free troposphere moisture and MSE westward. This is supported by Richardson et al. [2018], who find that this precipitation dipole can arise independently of soil moisture and circulation feedbacks, which operate on longer timescales.

(a) day 1 , hour $08--$ PBLH cont.

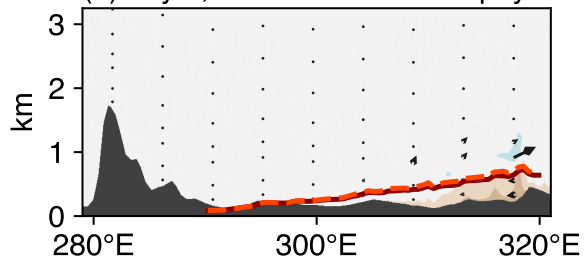

(c) day 1 , hour 10

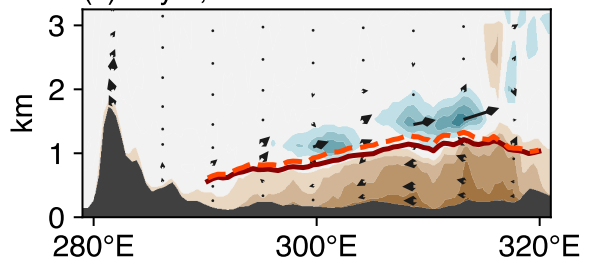

(e) day 1 , hour 12

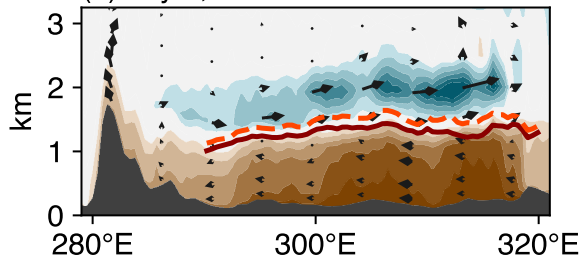

(g) day 1 , hour 14

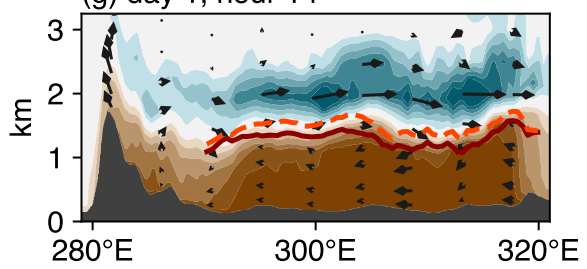

(b) day 1 , hour $09 \quad 1 \mathrm{~m} \mathrm{~s}^{-1} \longrightarrow$

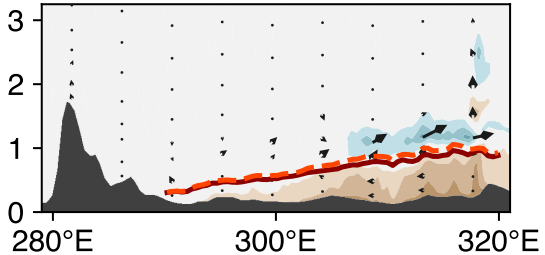

(d) day 1 , hour 11

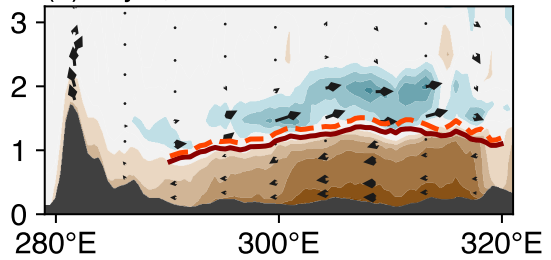

(f) day 1 , hour 13

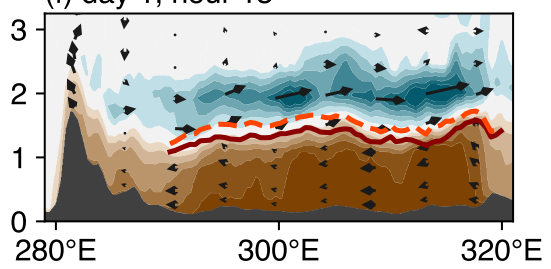

(h) day 1 , hour 15

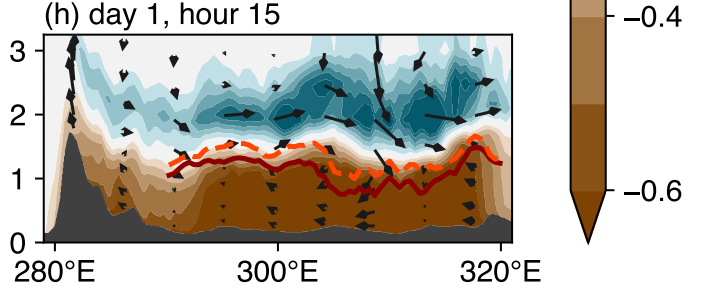

Figure 8. Ensemble mean change in moisture and winds during 08:00-15:00 of day 1. Plots depict hourly snapshots of moisture and wind vectors for the $\mathrm{CO}_{2}$,phys $-\mathrm{CO}_{2 \text {, cont }}$ runs in local time at $300^{\circ} \mathrm{E}$. Meridional means are taken between $10^{\circ} \mathrm{S}$ and $10^{\circ} \mathrm{N}$.

To understand how the physiological response behaves within the first 24 hours of a $\mathrm{CO}_{2}$ perturbation, Fig. 8 shows $\mathrm{CO}_{2}$,phys $-\mathrm{CO}_{2 \text {,cont }}$ moisture anomalies during the first morning and afternoon of the simulations. This view is especially noise-free and affords a clean analysis of the local originating processes. Between 08:00 and 10:00 local time, decreases in evapotranspiration cause immediate decreases in moisture throughout the boundary layer, preceding moisture increases in the lower free troposphere. Westerly wind 
anomalies above the boundary layer-indicating a slowing of the climatological jethave also developed throughout the Amazon basin by this time, though these circulation changes are confined to the lowest few $\mathrm{km}$ of the atmosphere (Fig. S5).

By 11:00, a vertical moisture dipole is established independently of deep convection, which has not yet spun up, and grows in magnitude over the course of the afternoon. As with the synoptic timescale, the moisture anomalies on day 1 can also be seen in low-level cloud fraction, shown in Fig. 9. During mid-morning and late afternoon, a dipole similar to that seen in Fig. 5b develops, implying that the characteristics seen over the synoptic timescale begin even within the first diurnal cycle. Before early morning, little change occurs to the boundary layer clouds, even though a low-level fog layer exists, implying that these moisture and cloud changes occur after sunrise on the first simulation day.

(a) day 1 , hour 08

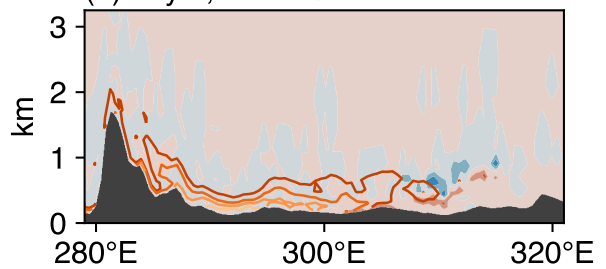

(c) day 1 , hour 10

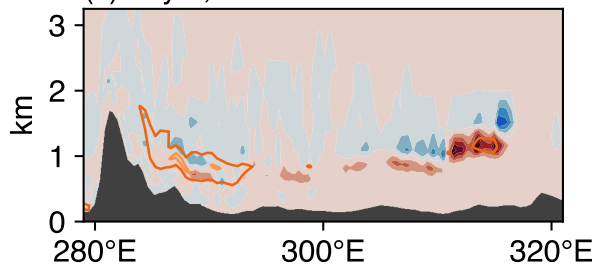

(e) day 1 , hour 12

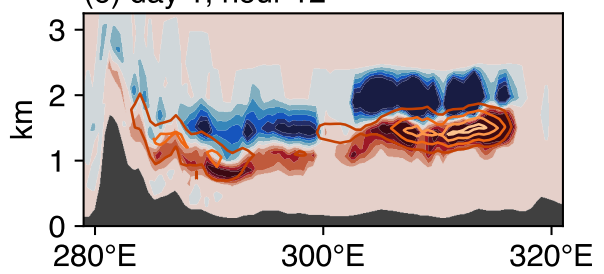

(g) day 1 , hour 14

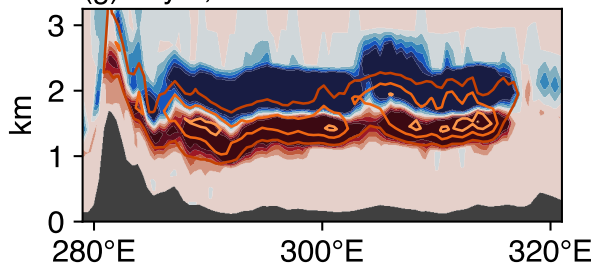

(b) day 1, hour 09

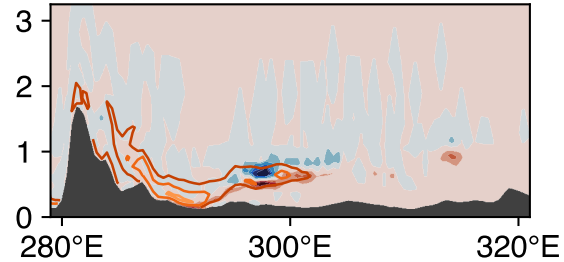

(d) day 1 , hour 11

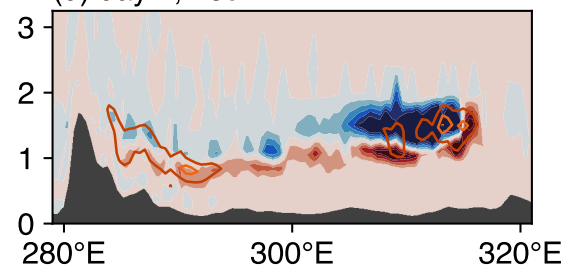

(f) day 1 , hour 13

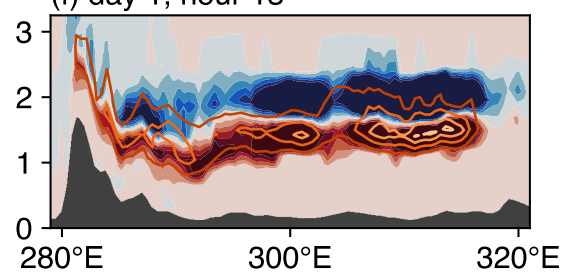

(h) day 1 , hour 15

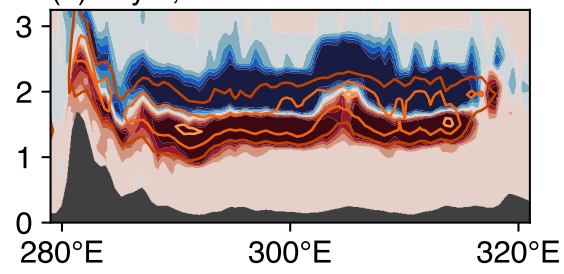

$-80$

-60 응
-40 옹

$-20$

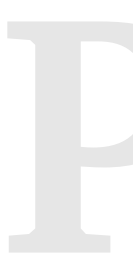

Figure 9. Ensemble mean change in cloud fraction during 08:00-15:00 of day 1. Plots depict hourly snapshots of moisture and wind vectors for the $\mathrm{CO}_{2}$,phys $-\mathrm{CO}_{2}$, cont runs in local time at $300^{\circ} \mathrm{E}$. Control simulation values from $\mathrm{CO}_{2}$, cont are shown as contour lines. Meridional means are taken between $10^{\circ} \mathrm{S}$ and $10^{\circ} \mathrm{N}$.

To see how the moisture buildup in the lower free troposphere affects shallow and deep convection, Fig. 10 shows the time rate of change of MSE, dMSE/dt, during the first 24 hours of local time. dMSE/dt is calculated as a centered finite difference time step for MSE $=L_{v} q+c_{p} T+g z$, where $L_{v}$ is the latent heat of vaporization $\left(2260 \mathrm{~kJ} \mathrm{~kg}^{-1}\right), c_{p}$ is the 
specific heat capacity of dry air $\left(1.006 \mathrm{~kJ} \mathrm{~kg}^{-1} \mathrm{~K}^{-1}\right)$, and $\mathrm{g}$ is the acceleration of gravity $\left(9.81 \mathrm{~m} \mathrm{~s}^{-2}\right)$. This calculation was done for the Amazon region shown in Fig. 2a. MSE is a conserved quantity in moist processes, neglecting the ice phase, and vertical differences in its rate of change provide a proxy for convective activity and energy transport in a system. In a typical diurnal cycle of rainfall over the Amazon, low- and mid-level cumulus convection driven by surface fluxes precondition the lower free tropospheric environment for deep convective clouds that produce rainfall during the local afternoon [e.g., Ghate and Kollias, 2016; Schiro et al., 2016], and this is seen by dMSE/dt contours in Fig. 10a, where boundary layer increases around local noon give rise to deep tropospheric MSE increases between 15:00 and 17:00, corresponding to afternoon rainfall. This behavior is most prominent in the dry and dry-to-wet transition seasons, when column-integrated moisture is generally lower and deep convection relies more heavily on evapotranspiration as a moisture source [Collow et al., 2016]. Deep convection on the first day draws on the the energy that has accumulated in the lower atmosphere during the morning, as evidenced by the negative dMSE/dt values at low levels during midday and early afternoon (Fig. 10a).

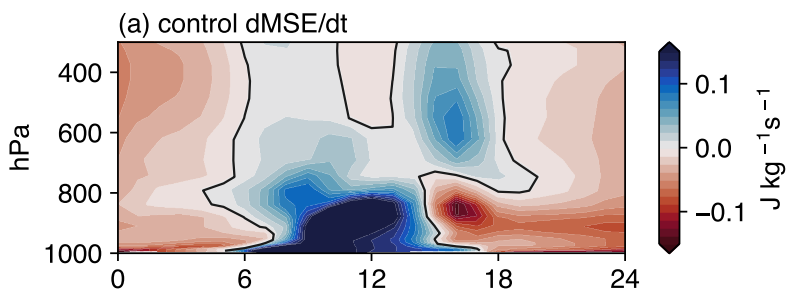

(b) $\triangle \mathrm{dMSE} / \mathrm{dt}$

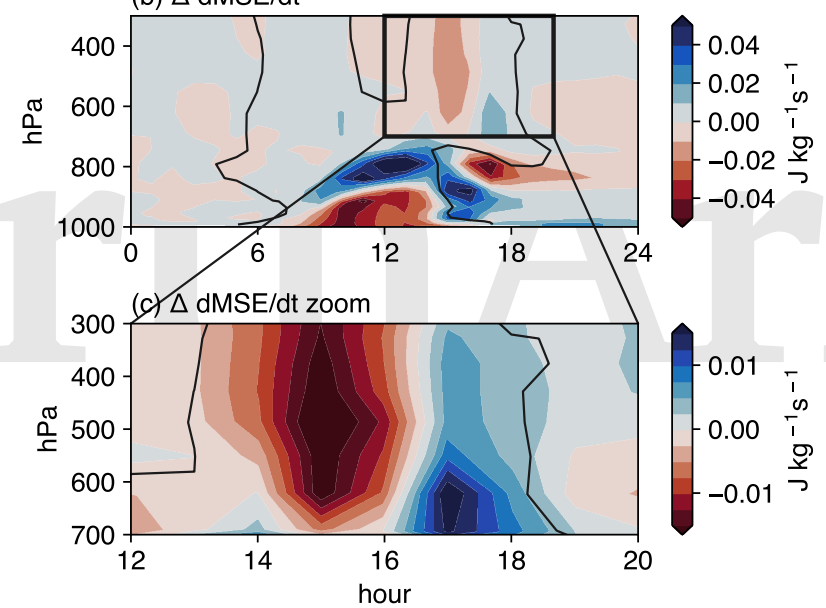

Figure 10. Ensemble mean dMSE/dt term during day 1, calculated for land-only grid points as an area mean for the Amazon region in Fig. 2a. (a) Control $\left(\mathrm{CO}_{2 \text {, cont }}\right)$ dMSE/dt between 1000 and $300 \mathrm{hPa}$. (b) Difference in dMSE/dt $\left(\mathrm{CO}_{2}\right.$,phys $-\mathrm{CO}_{2}$, cont $)$ between 1000 and $300 \mathrm{hPa}$. (c) Same as in (b) but during hours 12:00-20:00 and with a rescaled color bar.

In the physiological response, a decrease in boundary layer moisture has two consequences. First, enhanced mixing at the top of the boundary layer causes enhanced morning recharge of lower tropospheric vapor in the lower free troposphere, which causes shallow convection to reach higher into the atmosphere and leads to the vertical cloud fraction dipole seen in Figs. 5 and 9. Figure 10b shows that this dipole maximizes for the Amazon region between $\sim 10: 00$ and 14:00 and is associated with a net decrease in deep convective activity. The enlarged profile in Fig. 10c shows that deep convection experiences a maxi- 
mum decrease at 15:00, along with an anomalous increase in mid-level convection following approximately two hours later (around 17:00 between 600 and $700 \mathrm{hPa}$ ). Second, the much drier boundary layer on day 1 provides less overall moisture to deep convection, particularly in the afternoon (Fig. S5). The net effect is therefore to decrease deep convection and the moisture entrained in these clouds during the local afternoon. From the perspective of the 2-km thick layer immediately above the boundary layer, both of these effects on ambient vapor (increased morning recharge and reduced afternoon discharge) conspire to create a bridge mechanism to Andean wetting described earlier.

\subsection{Enhanced moisture flux in the lower free troposphere}

A final remaining puzzle on day 1, seen most clearly in Figs. 8 and 9, is the mechanism driving increased cloud fraction and water vapor above the boundary layer. The physiological response is throttling the vegetative moisture supply, yet moisture still increases above the boundary layer. What could be causing this?

Over the synoptic timescale (e.g., Figs. 5 and 7), it is logical to assume that decreased precipitation would remove less water vapor from the atmosphere, leaving an anomalous buildup as the precipitation decrease reaches an equilibrium. But the moisture increases above the boundary layer appear even on day 1 before precipitation shows any significant change (e.g., by 11:00 in Fig. 8d), so this is not a sufficient explanation for the first 24 hours. An additional source of water vapor could also be from a change in the rate of lateral convergence of lower free troposphere moisture from over the Atlantic Ocean, and while this is also likely important at longer timescales, it would take longer than the first $\sim 15$ hours to set up (11:00 over the central Amazon, a four-hour offest from UTC, corresponds to 15 full hours past the start of the simulation, which was 00:00 UTC). A moisture budget decomposition for the wind and moisture fields (not shown) is not helpful, either: neither vertical nor horizontal circulation changes (seen, for example, in the vectors in Figs. 8 and 9) can explain the moisture increases above the boundary layer, implying that resolved dynamics are not primary drivers of the lower free troposphere moisture anomalies.

The other likely candidates are either the boundary layer or convection scheme in the model. Both of these include subgrid-scale tendencies that affect the prognostic momentum, temperature, and moisture variables. To interrogate each scheme further, we use the sensitivity test from a 50-km WRF baseline run modified to output additional fields to moisture and temperature tendencies as well as diffusion coefficients and the terms that contribute to them (see the Supporting Information for more detail on these coefficients). We find that moisture and heating tendencies from the new Tiedtke convection scheme are small and do not explain the day 1 changes, and that these tendencies can be attributed almost entirely to the YSU boundary layer scheme (shown for the Amazon region in Fig. S6).

What causes this boundary layer-driven moisture increase? The answer appears to lie in the aspects of the simulation that govern mixing above the boundary layer top, specifically the diffusivity coefficients discussed for the YSU scheme in the supplementary information. The values of the mass diffusivity coefficient $\left(K_{t}\right.$; see the Supporting Information for a description) are shown for the first diurnal cycle over the Amazon region in Fig. 11a. Larger values of $K_{t}$ imply more vigorous subgrid-scale mixing. The control simulation shows a bottom-heavy profile, peaking in magnitude with deep convection near 15:00 local time. The $\mathrm{CO}_{2 \text {,phys }}-\mathrm{CO}_{2 \text {, cont }}$ changes are shown in Fig. 11b and align well with moisture increases that peak at $\sim 2 \mathrm{~km}$ height in the late afternoon of day 1 (Fig. 8). The equivalent diffusivity values for moisture and momentum (not shown) display similar patterns but are slightly smaller in magnitude. The YSU scheme includes a parameterization of free tropospheric diffusivity over the boundary layer with a magnitude governed in part by the vertical gradient of potential temperature at the boundary layer top 
(a) control $\mathrm{K}_{\mathrm{t}}$

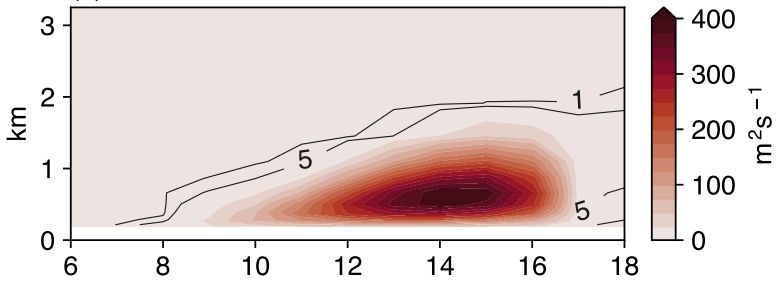

(b) $\Delta \mathrm{K}_{\mathrm{t}}$

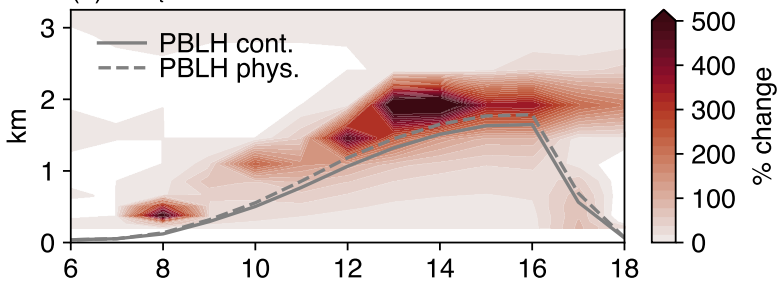

(c) $\Delta \theta$

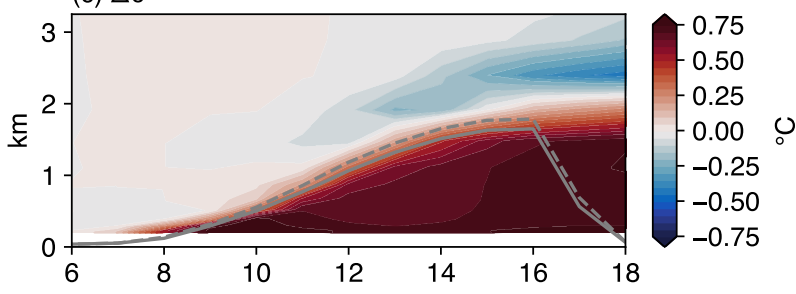

Figure 11. (a) $\mathrm{CO}_{2}$, cont eddy mixing coefficient values for mass $\left(K_{t}\right)$ as calculated in the YSU boundary layer scheme during the first diurnal cycle. Contour lines for values of 1 and $5 \mathrm{~m}^{2} \mathrm{~s}^{-1}$ are labeled. (b) Percent

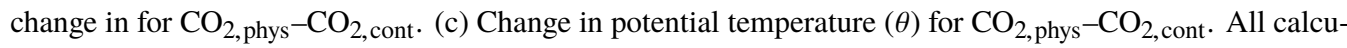
lations were done during day 1 over the Amazon region outlined in Fig. 2a. The planetary boundary layer height (PBLH) for the control and physiological forcing simulations is included in (b) and (c).

(Fig. 11c), which is used to determine the local stability of the atmosphere in the lower free troposphere and the bulk Richardson number that goes into calculations of eddy mixing coefficients.

Thus it is logical to speculate that the causality underpinning the morning moisture increase above the boundary layer is related to how thermal forcing by the physiological response impacts turbulent diffusivity via dry static stability near the boundary layer top. That is, the physiological response causes temperature to increase throughout the mixed layer, with largest changes at the surface and a diminishing magnitude approaching the boundary layer top. This in turn acts to resist dry static stability near the boundary layer top and promotes more vertical mixing by turbulent eddies, thus transporting more boundary layer water vapor further aloft. This enhanced diffusivity in the lower free troposphere is a result of intensified sensible heating at the surface, which increases the temperature and mixing of the boundary layer and leads to the vertical gradients in potential temperature seen in Fig. 11c.

\subsection{Sensitivity to boundary layer scheme}

The YSU scheme is typically regarded as one of the better overall performers in intercomparison studies [Hu et al., 2010; Gibbs et al., 2011; Xie et al., 2012; Coniglio et al., 2013; Cohen et al., 2015], though we have done additional testing using five alternative schemes to evaluate how sensitive our results are to a given boundary layer formulation. While there is variability in the magnitude of moisture and temperature change as well as 
boundary layer height in each set of simulations, the day 1 processes that increase moisture flux into the lower free troposphere appear consistent across most schemes with the exception of MYJ (Fig. S7), which lacks a vertical moisture dipole, possibly because it under-predicts the boundary layer height and entrainment at the boundary layer top [e.g., Hu et al., 2010; Coniglio et al., 2013]. Over a 10-day timescale, all schemes produce a similar drying region along the northeastern coast of tropical South America, though the magnitude of increase over the Andes and western tropical South America varies (Fig. S8). The familiar dipole can be seen in YSU, ACM2, and UW but not as clearly in TEMF or MYNN3, and it is fully absent in the MYJ scheme. These results suggest that the vertical moisture change dipole seen on day 1 may be a necessary starting point for Andean precipitation increases at the synoptic timescale, though other processes will be important in this response.

(a)

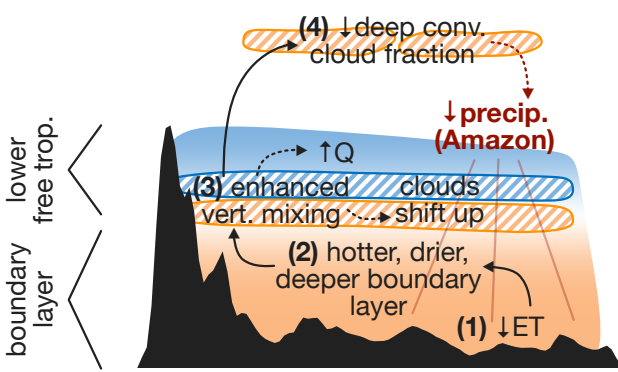

response on synoptic time scale

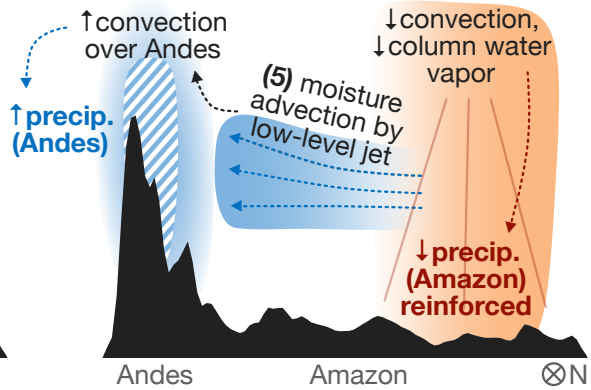

$\uparrow$ moisture $\uparrow$ cloud fraction 4....:in:: low-level jet

$\downarrow$ moisture $\downarrow \downarrow$ cloud fraction

(b)
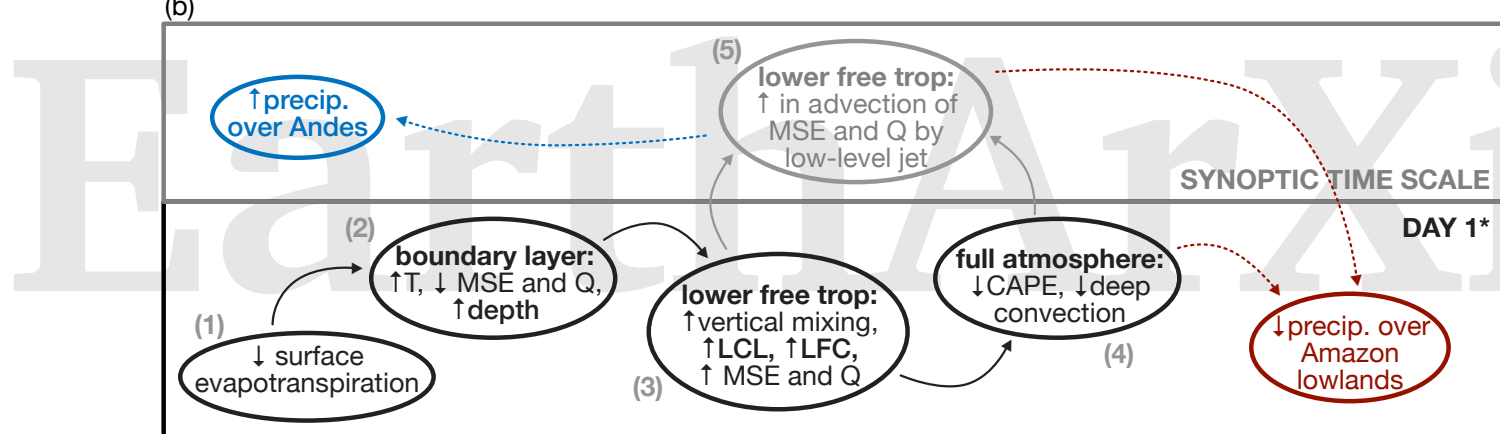

also applies to all days

Figure 12. Schematic diagram showing the day 1 and synoptic time scale responses over the Amazon and Andes. (a) Perspective is looking northward from the equator, and graphic represents meridional mean changes between $\sim 10^{\circ} \mathrm{S}-10^{\circ} \mathrm{N}$. Major physical processes discussed in the manuscript are numbered, and arrows indicate connections between these mechanisms and associated physical impacts. Solid arrows show connections between numbered processes, and dotted arrows show associated changes that occur simultaneously with a given process. (b) Mechanistic process chain with numbers corresponding to (a).

\section{Discussion}

\subsection{Synthesis of mechanism}

Figure 12 summarizes the mechanism discussed above with important steps numbered. On all days, including the first diurnal cycle, increased $\mathrm{CO}_{2}$ over the Amazon rain- 
forest canopy causes decreased evapotranspiration, leading to a warmer, drier, and deeper boundary layer. This increased boundary layer heating causes a larger vertical potential temperature gradient at the boundary layer top, driving enhanced dry turbulent mixing above that spreads these warmer temperatures vertically and increases moisture flux (Q) into the lower free troposphere. A temperature increase implies that more moisture is now necessary to reach condensation, and the lifting condensation level (LCL) and level of free convection (LFC) both increase. These boundary layer-driven changes also limit the amount of CAPE available to deep convection, which decreases precipitation over the Amazon lowlands within the first day. Over longer timescales (days to weeks), these changes in vertical mixing, combined with the decreased deep convective activity, leave a buildup of moisture and MSE in the lower free troposphere, which is then advected westward by the low-level jet. After several days, increased moisture advection by the jet leads to increased Andean precipitation throughout the full diurnal cycle, not constrained to afternoon convection. This advection simultaneously removes column atmospheric moisture from over the Amazon and reinforces decreased precipitation over the lowland rainforest in the east.

\subsection{Connection to convective margin shifts}

A useful way of framing the Amazon precipitation decrease is via theory on tropical convective margin shifts. The $4 \mathrm{~mm} \mathrm{day}^{-1}$ contour in Figs. $1 \mathrm{~b}, \mathrm{c}$ are a useful proxy for these margins, outlining regions of deep convection across which large gradients in boundary layer moisture and precipitation frequency occur [Chou et al., 2009]. Lintner and Neelin [2007] formulated a simple prototype for shifts of these margins under global warming and ENSO-driven variability, with an application to the eastern Amazon region. Using a simple model based on low-level wind and moisture inflow from the Atlantic onto the South American continent, they described how these margins shift inland through a mechanism affecting the moisture threshold necessary to sustain convection. In subsequent work, Lintner and Neelin [2009, 2010] looked more closely at the impact of soil moisture and the origin of Atlantic air masses on these margins.

The results from these papers help contextualize our mechanism in the wider literature on how $\mathrm{CO}_{2}$ perturbations will affect regions of tropical deep convection. While the papers mentioned above do not consider the physiological response directly, the same principles apply. In our simulations, throttling evapotranspiration through a physiological response leads to boundary layer moisture decreases (Fig. 5a) and lower tropospheric temperature increases (Fig. 5c). These two components combine to inhibit deep convection via an "upped-ante mechanism" [Neelin et al., 2003; Chou and Neelin, 2004]. In this process chain, a warmer troposphere increases the needed boundary layer moisture for convection to occur, but this moisture is not easily supplied because at these margins, lowlevel moisture is transported from drier regions and is unable to increase with temperatures sufficiently to maintain the same level of deep convection. Lintner and Neelin [2009] found these margins to be particularly sensitive to soil moisture, and we believe our perturbations to stomatal conductance have a similar effect on boundary layer moisture and deep convective likelihood. The process chain through which this convective constraint is expressed in our results is an intensification of above-boundary-layer mixing over the Amazon at the expense of deep convective activity. While a warmer boundary layer leads to modestly enhanced vertical motion, the overall effect is an upped ante for deep convection and its resulting inhibition throughout the rainforest basin. This is supported by the location of the red $4 \mathrm{~mm} \mathrm{day}^{-1}$ contour in Fig. 2a, along which the largest precipitation decreases occur. This theory can also account for the Andean precipitation increase: enhanced low-level moisture convergence over the Andean cordillera will lead to a higher likelihood of convective precipitation in a sense that is opposite to the upped-ante mechanism. 


\subsection{Implications for CMIP biases over the Amazon}

CMIP models are historically poor at simulating the dry-to-wet transition season over the Amazon as well as dry season moist processes, owing to inaccuracies in the surface energy budget [Yin et al., 2013], too little moisture throughout the troposphere [Lintner et al., 2017] and overly strong land-atmosphere coupling in ESMs [Ferguson et al., 2012; Levine et al., 2016]. For the Amazon in particular, the vegetation-driven precipitation activity discussed above plays a central role in the dry-to-wet transition season over the rainforest and is referred to as the "deep convective moisture pump" in Wright et al. [2017]. One might expect this process to be an important aspect of the observed increase in dry season length over the rainforest [Fu et al., 2013]. Land use change can also play a role in these observed changes. Replacing tropical forest with vegetation that transpires less or affects the energy balance in a way that increases the Bowen ratio could have a similar impact [e.g., Davidson et al., 2012; Nobre et al., 2016; Spracklen et al., 2018].

Taken together with our results, these lines of evidence indicate that climate model biases over the Amazon-which themselves show a wet Andes, dry Amazon dipole pattern akin to the physiological response [e.g., Yin et al., 2013] — may have their roots in improper simulation of vegetation-climate interaction. This notion is not new, but while many studies attribute the majority of the uncertainty to deep convective processes, we emphasize the equally important role that vegetation and boundary layer dynamics can play on the surface energy budget and resulting precipitation recycling, and that diurnal timescale processes may be as important as long-term feedbacks. The magnitude of end-of-century precipitation change over the Amazon is also uncertain in CMIP archives [e.g., Li et al., 2006; Joetzjer et al., 2013; Chen et al., 2018], and it is reasonable to believe that model differences associated with historical bias and end-of-century spread may share similar physical pathways.

\section{Conclusions}

Under increased atmospheric $\mathrm{CO}_{2}$, stomatal conductance decreases during sunlight hours when plants photosynthesize, causing less water loss through evapotranspiration. This effect is termed the physiological response, and recent work has identified it as a significant factor in projected Amazon precipitation decreases in ESMs, as well as Andean precipitation increases. The research on this mechanism to date has focused on ESM simulations with either a steady $\mathrm{CO}_{2}$ increase over the twenty-first century or $2 \times \mathrm{CO}_{2}$ equilibrium experiments that are integrated for multiple decades or longer. Both approaches convolve the fast, stomatal-driven response with longer-term soil moisture and possible ocean feedbacks, so we used abrupt $\mathrm{CO}_{2}$ increase experiments to isolate the initial days and weeks of the response, allowing for a cleaner view of the vegetation-driven landatmosphere interactions at play.

We find that the aspect of the physiological response causing decreased precipitation over the Amazon rainforest can happen quickly-within the first day after a $\mathrm{CO}_{2}$ increase. The anomalies developing during these hours prime the atmosphere for long-term changes to moisture and land-atmosphere interaction, and over the following days and weeks, increased precipitation develops over the Andes. This response appears to be independent of model type (regional versus global) and convective formulation (parameterized versus resolved), though it exhibits some sensitivity to boundary layer parameterization. We show that anomalies occurring within the first $\sim 10$ days are maintained over a decadal timescale in an ESM. The consistency of this physiological response implies that with increasing $\mathrm{CO}_{2}$ in the twenty-first century, the Amazon has the potential to undergo an ecosystem reorganization that may affect the region's vulnerability to drought, susceptibility to fire, and carbon storage capacity-and these changes can happen from vegetation-driven responses to $\mathrm{CO}_{2}$ alone. 
A facet of this response that we do not explicitly investigate is the annual cycle, including differences among wet, dry, and transition seasons. The equinox setup used here is applicable to the wet-to-dry and dry-to-wet transition months over the rainforest, underscoring the primary role that evapotranspiration and rainforest-boundary layer interaction will play under future $\mathrm{CO}_{2}$ increases. Taking a closer look at these interactions through the lens of the seasonal cycle will be a necessary next step, and it will better contextualize the role of the physiological response in dry season length and drought risk. Finally, given the dependence of the response on boundary layer dynamics, large eddy simulations that are able to resolve subgrid-scale moisture and temperature fluxes will also be an important complement to the models used here.

Our results suggest that this physiological response can be studied using short timescale model simulations that do not rely on longer-term soil moisture feedbacks. Persistent biases in Amazon climate, for example, may be better understood by focusing on sub-daily processes that describe land-atmosphere interaction and surface energy fluxes, which are pivotal in establishing persistent regional climate feedbacks that have historically received more attention in the Earth system modeling literature.

\section{Acknowledgments}

This research was funded by the U.S. Department of Energy (DOE) Office of Science, Biological and Environmental Research Division. MSP acknowledges additional support from the DOE Early Career Program grant DE-SC0012152 and the National Science Foundation (NSF) grant AGS-1734164. We also recognize high-performance computing support from Cheyenne (doi:10.5065/D6RX99HX), provided by NCAR's Computational and Information Systems Laboratory and sponsored by the NSF. Analysis was done in Python using numpy, scipy, wrf-python [Ladwig, 2017], and xarray [Hoyer and Hamman, 2017]. Plots were made using matplotlib and cartopy [Met Office, 2010], with color map support from cmocean [Thyng et al., 2016]. Scripts used to create WRF and CESM runs as well as all figures are hosted on GitHub at https://github.com/bairdlangenbrunner/ amazon-phys-response-paper. Output from model simulations can be obtained by contacting B. Langenbrunner.

\section{References}

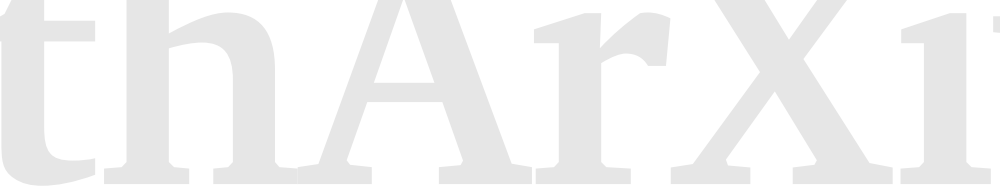

Abe, M., H. Shiogama, T. Yokohata, S. Emori, and T. Nozawa (2015), Asymmetric impact of the physiological effect of carbon dioxide on hydrological responses to instantaneous negative and positive $\mathrm{CO}_{2}$ forcing, Climate Dynamics, 45(7-8), 2181-2192.

Angevine, W. M., H. Jiang, and T. Mauritsen (2010), Performance of an eddy diffusivitymass flux scheme for shallow cumulus boundary layers, Monthly Weather Review, 138(7), 2895-2912.

Bechtold, P., J.-P. Chaboureau, A. Beljaars, A. Betts, M. Köhler, M. Miller, and J.-L. Redelsperger (2004), The simulation of the diurnal cycle of convective precipitation over land in a global model, Quarterly Journal of the Royal Meteorological Society, 130(604), 3119-3137.

Bechtold, P., M. Köhler, T. Jung, F. Doblas-Reyes, M. Leutbecher, M. J. Rodwell, F. Vitart, and G. Balsamo (2008), Advances in simulating atmospheric variability with the ECMWF model: From synoptic to decadal time-scales, Quarterly Journal of the Royal Meteorological Society, 134(634), 1337-1351.

Bechtold, P., N. Semane, P. Lopez, J.-P. Chaboureau, A. Beljaars, and N. Bormann (2014), Representing equilibrium and nonequilibrium convection in large-scale models, Journal of the Atmospheric Sciences, 71(2), 734-753.

Berner, J., S.-Y. Ha, J. Hacker, A. Fournier, and C. Snyder (2011), Model uncertainty in a mesoscale ensemble prediction system: Stochastic versus multiphysics representations, Monthly Weather Review, 139(6), 1972-1995. 
Betts, R., P. Cox, M. Collins, P. Harris, C. Huntingford, and C. Jones (2004), The role of ecosystem-atmosphere interactions in simulated Amazonian precipitation decrease and forest dieback under global climate warming, Theoretical and Applied Climatology, 78(1-3), 157-175.

Bonfils, C., G. Anderson, B. D. Santer, T. J. Phillips, K. E. Taylor, M. Cuntz, M. D. Zelinka, K. Marvel, B. I. Cook, I. Cvijanovic, et al. (2017), Competing influences of anthropogenic warming, ENSO, and plant physiology on future terrestrial aridity, Journal of Climate, 30(17), 6883-6904.

Bretherton, C. S., and S. Park (2009), A new moist turbulence parameterization in the Community Atmosphere Model, Journal of Climate, 22(12), 3422-3448.

Bretherton, C. S., M. E. Peters, and L. E. Back (2004), Relationships between water vapor path and precipitation over the tropical oceans, Journal of Climate, 17(7), 1517-1528.

Brubaker, K. L., D. Entekhabi, and P. Eagleson (1993), Estimation of continental precipitation recycling, Journal of Climate, 6(6), 1077-1089.

Chen, Y., B. Langenbrunner, and J. T. Randerson (2018), Future drying in Central America and northern South America linked with Atlantic meridional overturning circulation, Geophysical Research Letters, in press.

Chou, C., and J. D. Neelin (2004), Mechanisms of global warming impacts on regional tropical precipitation, Journal of Climate, 17(13), 2688-2701.

Chou, C., J. D. Neelin, C.-A. Chen, and J.-Y. Tu (2009), Evaluating the "rich-get-richer" mechanism in tropical precipitation change under global warming, Journal of Climate, 22(8), 1982-2005.

Cohen, A. E., S. M. Cavallo, M. C. Coniglio, and H. E. Brooks (2015), A review of planetary boundary layer parameterization schemes and their sensitivity in simulating southeastern US cold season severe weather environments, Weather and Forecasting, 30(3), 591-612.

Collow, A. B. M., M. A. Miller, and L. C. Trabachino (2016), Cloudiness over the Amazon rainforest: Meteorology and thermodynamics, Journal of Geophysical Research: Atmospheres, 121(13), 7990-8005.

Coniglio, M. C., J. Correia Jr, P. T. Marsh, and F. Kong (2013), Verification of convection-allowing WRF model forecasts of the planetary boundary layer using sounding observations, Weather and Forecasting, 28(3), 842-862.

Davidson, E. A., A. C. de Araújo, P. Artaxo, J. K. Balch, I. F. Brown, M. M. Bustamante, M. T. Coe, R. S. DeFries, M. Keller, M. Longo, et al. (2012), The Amazon basin in transition, Nature, 481(7381), 321.

Dirzo, R., and P. H. Raven (2003), Global state of biodiversity and loss, Annual Review of Environment and Resources, 28(1), 137-167.

Duda, J. D., X. Wang, F. Kong, M. Xue, and J. Berner (2016), Impact of a stochastic kinetic energy backscatter scheme on warm season convection-allowing ensemble forecasts, Monthly Weather Review, 144(5), 1887-1908.

Eltahir, E. A., and R. L. Bras (1994), Precipitation recycling in the Amazon basin, Quarterly Journal of the Royal Meteorological Society, 120(518), 861-880.

Ferguson, C. R., E. F. Wood, and R. K. Vinukollu (2012), A global intercomparison of modeled and observed land-atmosphere coupling, Journal of Hydrometeorology, 13(3), 749-784.

Field, C. B., R. B. Jackson, and H. A. Mooney (1995), Stomatal responses to increased $\mathrm{CO}_{2}$ : Implications from the plant to the global scale, Plant, Cell \& Environment, 18(10), 1214-1225.

Field, C. B., M. J. Behrenfeld, J. T. Randerson, and P. Falkowski (1998), Primary production of the biosphere: integrating terrestrial and oceanic components, Science, 281(5374), 237-240.

Fu, R., L. Yin, W. Li, P. A. Arias, R. E. Dickinson, L. Huang, S. Chakraborty, K. Fernandes, B. Liebmann, R. Fisher, and R. B. Myneni (2013), Increased dry-season length over southern Amazonia in recent decades and its implication for future climate projec- 
tion, Proceedings of the National Academy of Sciences, doi:10.1073/pnas.1302584110.

Ghate, V. P., and P. Kollias (2016), On the controls of daytime precipitation in the Amazonian dry season, Journal of Hydrometeorology, 17(12), 3079-3097.

Gibbs, J. A., E. Fedorovich, and A. M. Van Eijk (2011), Evaluating Weather Research and Forecasting (WRF) model predictions of turbulent flow parameters in a dry convective boundary layer, Journal of Applied Meteorology and Climatology, 50(12), 2429-2444.

Holloway, C. E., and J. D. Neelin (2009), Moisture vertical structure, column water vapor, and tropical deep convection, Journal of the Atmospheric Sciences, 66(6), 1665-1683.

Hong, S.-Y., and J.-O. J. Lim (2006), The WRF single-moment 6-class microphysics scheme (WSM6), Japan Korean Meteorological Society, 42(2), 129-151.

Hong, S.-Y., Y. Noh, and J. Dudhia (2006), A new vertical diffusion package with an explicit treatment of entrainment processes, Monthly Weather Review, 134(9), 2318-2341.

Hoyer, S., and J. Hamman (2017), xarray: ND labeled arrays and datasets in Python, Journal of Open Research Software, 5(1).

Hu, X.-M., J. W. Nielsen-Gammon, and F. Zhang (2010), Evaluation of three planetary boundary layer schemes in the WRF model, Journal of Applied Meteorology and Climatology, 49(9), 1831-1844.

Iacono, M. J., J. S. Delamere, E. J. Mlawer, M. W. Shephard, S. A. Clough, and W. D. Collins (2008), Radiative forcing by long-lived greenhouse gases: Calculations with the AER radiative transfer models, Journal of Geophysical Research: Atmospheres, 113(D13).

Janjić, Z. I. (1994), The step-mountain eta coordinate model: Further developments of the convection, viscous sublayer, and turbulence closure schemes, Monthly Weather Review, 122(5), 927-945.

Joetzjer, E., H. Douville, C. Delire, and P. Ciais (2013), Present-day and future Amazonian precipitation in global climate models: CMIP5 versus CMIP3, Climate Dynamics, 41(11-12), 2921-2936.

Kanamitsu, M., A. Kumar, H.-M. H. Juang, J.-K. Schemm, W. Wang, F. Yang, S.-Y. Hong, P. Peng, W. Chen, S. Moorthi, and M. Ji (2002), NCEP Dynamical Seasonal Forecast System 2000, Bulletin of the American Meteorological Society, 83(7), 1019-1037.

Kooperman, G. J., Y. Chen, F. M. Hoffman, C. D. Koven, K. Lindsay, M. S. Pritchard, A. L. Swann, and J. T. Randerson (2018), Forest response to rising $\mathrm{CO}_{2}$ drives zonally asymmetric rainfall change over tropical land, Nature Climate Change, 8(5), 434-440.

Ladwig, W. (2017), wrf-python (version 1.2.0), Boulder, Colorado, doi:10.5065/ D6W094P1.

Lee, J.-E., R. S. Oliveira, T. E. Dawson, and I. Fung (2005), Root functioning modifies seasonal climate, Proceedings of the National Academy of Sciences, 102(49), 17,57617,581 .

Lemordant, L., P. Gentine, A. S. Swann, B. I. Cook, and J. Scheff (2018), Critical impact of vegetation physiology on the continental hydrologic cycle in response to increasing $\mathrm{CO}_{2}$, Proceedings of the National Academy of Sciences, doi:10.1073/pnas.1720712115.

Levine, P. A., J. T. Randerson, S. C. Swenson, and D. M. Lawrence (2016), Evaluating the strength of the land-atmosphere moisture feedback in Earth system models using satellite observations, Hydrology and Earth System Sciences, 20(12), 4837-4856.

Li, W., R. Fu, and R. E. Dickinson (2006), Rainfall and its seasonality over the Amazon in the 21st century as assessed by the coupled models for the IPCC AR4, Journal of Geophysical Research: Atmospheres, 111(D2).

Lintner, B. R., and J. D. Neelin (2007), A prototype for convective margin shifts, Geophysical Research Letters, 34(L05812).

Lintner, B. R., and J. D. Neelin (2009), Soil moisture impacts on convective margins, Journal of Hydrometeorology, 10(4), 1026-1039.

Lintner, B. R., and J. D. Neelin (2010), Tropical South America-Atlantic sector convective margins and their relationship to low-level inflow, Journal of Climate, 23(10), 26712685 . 
Lintner, B. R., D. K. Adams, K. A. Schiro, A. M. Stansfield, A. Rocha, A. Alciélio, and J. D. Neelin (2017), Relationships among climatological vertical moisture structure, column water vapor, and precipitation over the central Amazon in observations and CMIP5 models, Geophysical Research Letters, 44(4), 1981-1989.

Lu, X., L. Wang, and M. F. McCabe (2016), Elevated $\mathrm{CO}_{2}$ as a driver of global dryland greening, Scientific Reports, 6, 20,716.

Met Office (2010), Cartopy: a cartographic python library with a matplotlib interface, Exeter, Devon.

Nakanishi, M., and H. Niino (2006), An improved Mellor-Yamada level-3 model: Its numerical stability and application to a regional prediction of advection fog, BoundaryLayer Meteorology, 119(2), 397-407.

Nakanishi, M., and H. Niino (2009), Development of an improved turbulence closure model for the atmospheric boundary layer, Journal of the Meteorological Society of Japan, 87(5), 895-912.

Neale, R. B., J. H. Richter, A. J. Conley, S. Park, P. H. Lauritzen, A. Gettelman, D. L. Williamson, P. J. Rasch, S. J. Vavrus, M. A. Taylor, W. D. Collins, M. Zhang, and S.J. Lin (2010), Description of the NCAR Community Atmosphere Model (CAM 4.0), NCAR Technical Note TN-485, National Center for Atmospheric Research, Boulder, Colorado.

Neelin, J. D., C. Chou, and H. Su (2003), Tropical drought regions in global warming and El Niño teleconnections, Geophysical Research Letters, 30(24), 2275.

Niu, G.-Y., Z.-L. Yang, K. E. Mitchell, F. Chen, M. B. Ek, M. Barlage, A. Kumar, K. Manning, D. Niyogi, E. Rosero, et al. (2011), The community Noah land surface model with multiparameterization options (Noah-MP): 1. Model description and evaluation with local-scale measurements, Journal of Geophysical Research: Atmospheres, 116(D12).

Nobre, C. A., G. Sampaio, L. S. Borma, J. C. Castilla-Rubio, J. S. Silva, and M. Cardoso (2016), Land-use and climate change risks in the Amazon and the need of a novel sustainable development paradigm, Proceedings of the National Academy of Sciences, 113(39), 10,759-10,768.

Oleson, K. W., D. M. Lawrence, B. Gordon, M. G. Flanner, E. Kluzek, J. Peter, S. Levis, S. C. Swenson, E. Thornton, J. Feddema, C. L. Heald, F. Hoffman, J.-F. Lamarque, N. Mahowald, G.-Y. Niu, T. Qian, J. Randerson, S. Running, K. Sakaguchi, A. Slater, R. Stöckli, A. Wang, Z.-L. Yang, X. Zeng, and X. Zeng (2010), Technical description of version 4.0 of the Community Land Model (CLM), NCAR Technical Note TN-478, National Center for Atmospheric Research, Boulder, Colorado.

Pagani, M., Z. Liu, J. LaRiviere, and A. C. Ravelo (2010), High Earth-system climate sensitivity determined from Pliocene carbon dioxide concentrations, Nature Geoscience, 3(1), 27.

Pinto, E., Y. Shin, S. Cowling, and C. Jones (2009), Past, present and future vegetationcloud feedbacks in the Amazon Basin, Climate Dynamics, 32(6), 741-751.

Pleim, J. E. (2007a), A combined local and nonlocal closure model for the atmospheric boundary layer. Part I: Model description and testing, Journal of Applied Meteorology and Climatology, 46(9), 1383-1395.

Pleim, J. E. (2007b), A combined local and nonlocal closure model for the atmospheric boundary layer. Part II: Application and evaluation in a mesoscale meteorological model, Journal of Applied Meteorology and Climatology, 46(9), 1396-1409.

$\mathrm{Pu}, \mathrm{B}$., and R. E. Dickinson (2014), Hydrological changes in the climate system from leaf responses to increasing $\mathrm{CO}_{2}$, Climate Dynamics, 42(7-8), 1905-1923.

Richardson, T., P. Forster, T. Andrews, O. Boucher, G. Faluvegi, D. Fläschner, M. Kasoar, A. Kirkevåg, J.-F. Lamarque, G. Myhre, et al. (2018), Carbon dioxide physiological forcing dominates projected eastern Amazonian drying, Geophysical Research Letters, 45(6), 2815-2825. 
Schiro, K. A., J. D. Neelin, D. K. Adams, and B. R. Lintner (2016), Deep convection and column water vapor over tropical land versus tropical ocean: A comparison between the Amazon and the tropical western Pacific, Journal of the Atmospheric Sciences, 73(10), 4043-4063.

Sellers, P., L. Bounoua, G. Collatz, D. Randall, D. Dazlich, S. Los, J. Berry, I. Fung, C. Tucker, C. Field, et al. (1996), Comparison of radiative and physiological effects of doubled atmospheric $\mathrm{CO}_{2}$ on climate, Science, 271(5254), 1402-1406.

Skinner, C. B., C. J. Poulsen, R. Chadwick, N. S. Diffenbaugh, and R. P. Fiorella (2017), The role of plant $\mathrm{CO}_{2}$ physiological forcing in shaping future daily-scale precipitation, Journal of Climate, 30(7), 2319-2340.

Skinner, C. B., C. J. Poulsen, and J. S. Mankin (2018), Amplification of heat extremes by plant $\mathrm{CO}_{2}$ physiological forcing, Nature Communications, 9(1), 1094.

Sobel, A. H., J. Nilsson, and L. M. Polvani (2001), The weak temperature gradient approximation and balanced tropical moisture waves, Journal of the Atmospheric Sciences, 58(23), 3650-3665.

Spracklen, D., J. Baker, L. Garcia-Carreras, and J. Marsham (2018), The effects of tropical vegetation on rainfall, Annual Review of Environment and Resources, (0).

Staal, A., O. A. Tuinenburg, J. H. Bosmans, M. Holmgren, E. H. van Nes, M. Scheffer, D. C. Zemp, and S. C. Dekker (2018), Forest-rainfall cascades buffer against drought across the Amazon, Nature Climate Change, p. 1.

Swann, A. L., F. M. Hoffman, C. D. Koven, and J. T. Randerson (2016), Plant responses to increasing $\mathrm{CO}_{2}$ reduce estimates of climate impacts on drought severity, Proceedings of the National Academy of Sciences, 113(36), 10,019-10,024.

Taylor, K. E., R. J. Stouffer, and G. A. Meehl (2012), An Overview of CMIP5 and the Experiment Design, Bulletin of the American Meteorological Society, 93(4), 485-498.

Thyng, K. M., C. A. Greene, R. D. Hetland, H. M. Zimmerle, and S. F. DiMarco (2016), True colors of oceanography: Guidelines for effective and accurate colormap selection, Oceanography, 29(3), 9-13.

Tiedtke, M. (1989), A comprehensive mass flux scheme for cumulus parameterization in large-scale models, Monthly Weather Review, 117(8), 1779-1800.

Tripati, A. K., C. D. Roberts, and R. A. Eagle (2009), Coupling of $\mathrm{CO}_{2}$ and ice sheet stability over major climate transitions of the last 20 million years, Science, 326(5958), 1394-1397.

Van der Ent, R. J., H. H. Savenije, B. Schaefli, and S. C. Steele-Dunne (2010), Origin and fate of atmospheric moisture over continents, Water Resources Research, 46(9).

Vera, C., J. Baez, M. Douglas, C. Emmanuel, J. Marengo, J. Meitin, M. Nicolini, J. Nogues-Paegle, J. Paegle, O. Penalba, et al. (2006), The South American low-level jet experiment, Bulletin of the American Meteorological Society, 87(1), 63-78.

Wright, J. S., R. Fu, J. R. Worden, S. Chakraborty, N. E. Clinton, C. Risi, Y. Sun, and L. Yin (2017), Rainforest-initiated wet season onset over the southern Amazon, Proceedings of the National Academy of Sciences, 114(32), 8481-8486.

Xie, B., J. C. Fung, A. Chan, and A. Lau (2012), Evaluation of nonlocal and local planetary boundary layer schemes in the WRF model, Journal of Geophysical Research: Atmospheres, 117(D12).

Yang, Z.-L., G.-Y. Niu, K. E. Mitchell, F. Chen, M. B. Ek, M. Barlage, L. Longuevergne, K. Manning, D. Niyogi, M. Tewari, et al. (2011), The community Noah land surface model with multiparameterization options (Noah-MP): 2. Evaluation over global river basins, Journal of Geophysical Research: Atmospheres, 116(D12).

Yin, L., R. Fu, E. Shevliakova, and R. Dickinson (2013), How well can CMIP5 simulate precipitation and its controlling processes over tropical South America?, Climate Dynamics, 41(11-12), 3127-3142.

Zemp, D., C.-F. Schleussner, H. Barbosa, R. Van der Ent, J. F. Donges, J. Heinke, G. Sampaio, and A. Rammig (2014), On the importance of cascading moisture recycling in South America, Atmospheric Chemistry and Physics, 14(23), 13,337-13,359. 
Zhang, C., Y. Wang, and K. Hamilton (2011), Improved representation of boundary layer clouds over the southeast Pacific in ARW-WRF using a modified Tiedtke cumulus parameterization scheme, Monthly Weather Review, 139(11), 3489-3513.
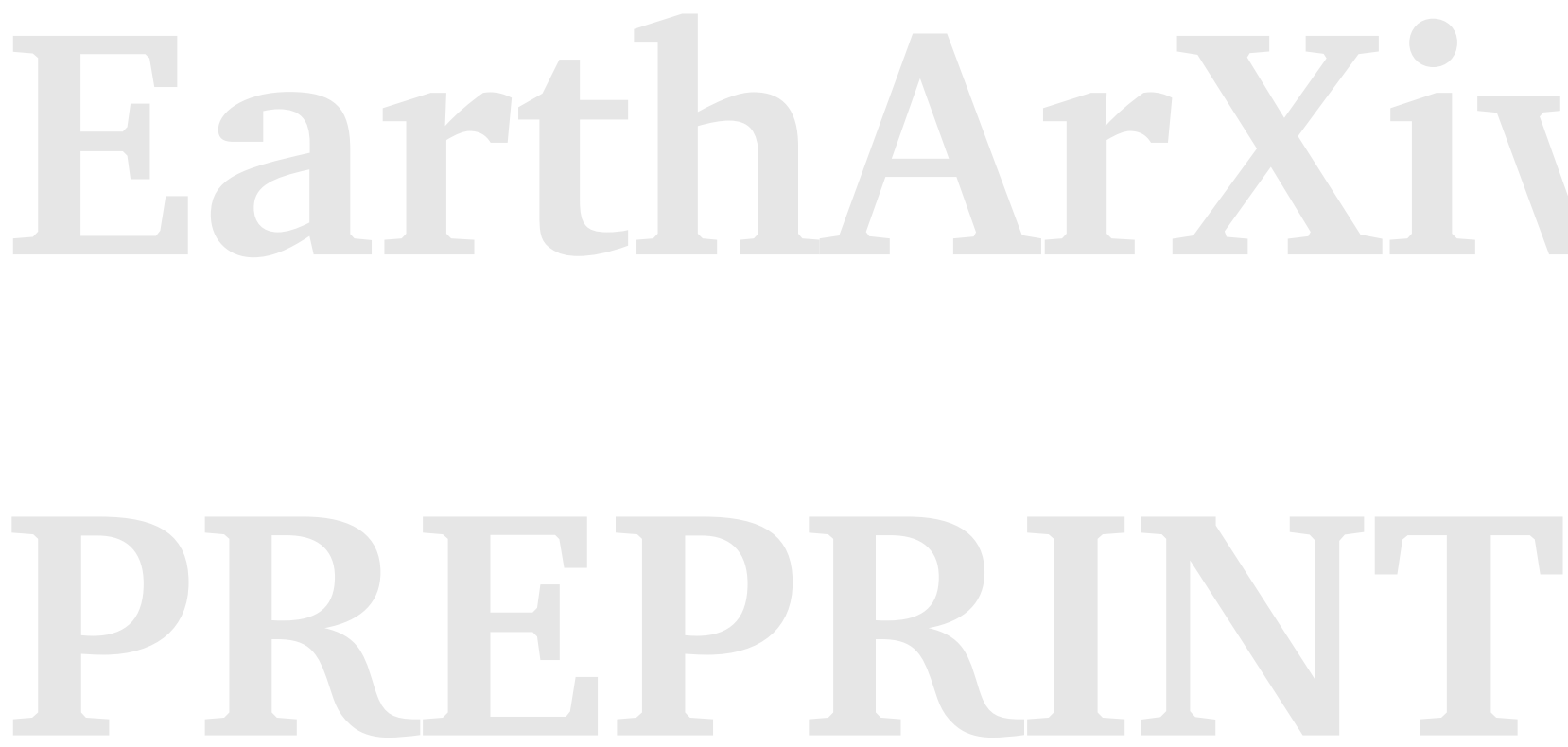